\title{
Size-dependent chemical ageing of oleic acid aerosol under dry and humidified conditions
}

\author{
Suad S. Al-Kindi ${ }^{1}$, Francis D. Pope ${ }^{1}$, David C. Beddows ${ }^{1, \text { a }}$, William J. Bloss ${ }^{1}$, and Roy M. Harrison ${ }^{1, b}$ \\ ${ }^{1}$ School of Geography, Earth and Environmental Sciences, University of Birmingham, Edgbaston, Birmingham B15 2TT, UK \\ a also at: National Centre for Atmospheric Science, UK \\ balso at: Department of Environmental Sciences/Center of Excellence in Environmental Studies, King Abdulaziz University, \\ Jeddah, 21589, Saudi Arabia
}

Correspondence to: Francis D. Pope (f.pope@bham.ac.uk)

Received: 16 March 2016 - Published in Atmos. Chem. Phys. Discuss.: 22 March 2016

Revised: 10 November 2016 - Accepted: 17 November 2016 - Published: 16 December 2016

\begin{abstract}
A chemical reaction chamber system has been developed for the processing of oleic acid aerosol particles with ozone under two relative humidity conditions: dry and humidified to $65 \%$. The apparatus consists of an aerosol flow tube, in which the ozonolysis occurs, coupled to a scanning mobility particle sizer (SMPS) and an aerosol time-of-flight mass spectrometer (ATOFMS) which measure the evolving particle size and composition. Under both relative humidity conditions, ozonolysis results in a significant decrease in particle size and mass which is consistent with the formation of volatile products that partition from the particle to the gas phase. Mass spectra derived from the ATOFMS reveal the presence of the typically observed reaction products: azelaic acid, nonanal, oxononanoic acid and nonanoic acid, as well as a range of higher molecular weight products deriving from the reactions of reaction intermediates with oleic acid and its oxidation products. These include octanoic acid and 9- and 10-oxooctadecanoic acid, as well as products of considerably higher molecular weight. Quantitative evaluation of product yields with the ATOFMS shows a marked dependence upon both particle size association (from 0.3 to $2.1 \mu \mathrm{m}$ diameter) and relative humidity. Under both relative humidity conditions, the percentage residual of oleic acid increases with increasing particle size and the main lower molecular weight products are nonanal and oxononanoic acid. Under dry conditions, the percentage of higher molecular weight products increases with increasing particle size due to the poorer internal mixing of the larger particles. Under humidified conditions, the percentage of unreacted oleic acid is greater, except in the smallest particle fraction, with little formation of
\end{abstract}

high molecular weight products relative to the dry particles. It is postulated that water reacts with reactive intermediates, competing with the processes which produce high molecular weight products. Whilst the oleic acid model aerosol system is of limited relevance to complex internally mixed atmospheric aerosol, the generic findings presented in this paper give useful insights into the nature of heterogeneous chemical processes.

\section{Introduction}

Atmospheric aerosol particles play critical roles in air quality, visibility, human health, regional and global climate, cloud condensation nuclei ability, precipitation events, atmospheric acid deposition, optical properties, atmospheric energy balance, and stratospheric ozone depletion (Harrison, 2014). Aerosol particles are typically composed of a mixture of inorganic and organic material. The organic component of aerosol is highly complex and may contain thousands of different chemical species of both biogenic and anthropogenic origin (Goldstein and Galbally, 2007). These organic components cause aerosol particles to exhibit a wide range of chemical properties due to their differing composition.

Primary organic aerosol (POA) particles are emitted directly from anthropogenic and biological sources (Pöschl, 2011). It is composed of a wide range of hydrocarbons, partially oxidised organics, and elemental carbon primarily related to combustion processes including burning of fossil fuels, cooking, domestic heating, and biomass burning. 
Natural biogenic sources of organic aerosol particles include plants and vegetation, the ocean surface, volcanic eruptions, and wind-driven dust (Pöschl, 2011). By contrast, secondary organic aerosol (SOA) particles are formed in the atmosphere from biogenic and anthropogenic gaseous precursors. Several pathways for the transformation of aerosol particles in the atmosphere have been identified that may alter their chemical and physical properties, in general causing hydrophobic-to-hydrophilic conversion of organic components. These pathways include gas-phase reactions, condensed-phase reactions, multiphase reactions, and multigenerational chemistry, which has received attention recently because it is the least understood (Rudich, 2003; Petters et al., 2006; Kroll and Seinfeld, 2008; Carlton et al., 2010; Koop et al., 2011; Kolb and Worsnop, 2012).

The ozonolysis of oleic acid (OL) aerosol is a much studied heterogeneous reaction which provides a readily accessible test system for the understanding of atmospheric processing of organic aerosol under a range of environmental conditions (Hearn and Smith, 2004; Katrib et al., 2004; Ziemann, 2005; Gonzalez-Labrada et al., 2007; Zahardis and Petrucci, 2007; Vesna et al., 2009; Pfrang et al., 2010; Lee et al., 2012; Chan et al., 2013; Hosny et al., 2013; Mendez et al., 2014; Hosny et al., 2016) - although oleic acid itself is only introduced into the atmosphere in small quantities via the heating of fat and cooking oil. OL studies have, for example, explored the effects of the droplet state (Katrib et al., 2005a), relative humidity (RH; Vesna et al., 2009; Lee et al., 2012), OL and ozone concentration (Lee and Chan, 2007; Mendez et al., 2014), and extent of chemical ageing (Reynolds et al., 2006) upon the OL-ozone system. The kinetics (Moise and Rudich, 2002; Gonzalez-Labrada et al., 2007), reaction mechanism and products (Hearn and Smith, 2004; Katrib et al., 2004; Hung et al., 2005; Zahardis et al., 2005, 2006; Ziemann, 2005; Zahardis and Petrucci, 2007, Wang et al., 2016), particle morphology and hygroscopicity (Dennis-Smither et al., 2012a), and viscosity (Hosny et al., 2013, 2016) have also been investigated.

The initial stages in the mechanism of particulate-phase OL ozonolysis are comparatively well understood (Moise and Rudich, 2002; Smith et al., 2002; Hearn and Smith, 2004; Katrib et al., 2004; Ziemann, 2005; Grimm et al., 2006; Nash et al., 2006; Hung and Ariya, 2007; Zahardis and Petrucci, 2007; Vesna et al., 2008; Lee et al., 2012); see Scheme 1. The initial step in the reaction is the addition of ozone across the double bond of OL forming an unstable primary ozonide (POZ). Subsequently, the POZ decomposes, via two potential routes, through cleavage of the $\mathrm{C}-\mathrm{C}$ bond alongside one of the two $\mathrm{O}-\mathrm{O}$ bonds. Both routes generate an aldehyde and an excited Criegee intermediate (CI) as products, but with differing chemical identity depending upon which $\mathrm{O}-\mathrm{O}$ bond is broken. In reaction route 1 (Scheme 1), nonanal (NN) and CI1 are formed; the CI1 can isomerise to form stabilised azelaic acid (AA), a cyclic acyloxy hydroperoxide (CAHP), or octanoic acid (OcA) and carbon dioxide (Gonzalez-Labrada et al., 2007). Alternatively, CI1 may be scavenged via numerous potential association reactions with the co-produced aldehyde, other carboxylic-functionalised moieties, (further) OL molecule double bonds, solvents, or via self-reaction. This extensive secondary chemistry reflects the reactivity of CIs (Zahardis and Petrucci, 2007). Similarly, in reaction route 2, oxononanoic acid (ON) and excited CI2 are formed, and CI2 decomposes by forming stabilised nonanoic acid (NA), or may be scavenged via similar pathways as described above for CI1. The principal reaction products of OL ozonolysis are therefore NN, AA, ON, and NA. There are also numerous reports in the literature of the formation of higher molecular weight products (Hung et al., 2005; Reynolds, et al., 2006; Zahardis et al., 2005) including esters (Hung et al., 2010) and peroxides (Reynolds et al., 2006; Vesna et al., 2009; Zahardis et al., 2005, 2006; Ziemann, 2005). Although OL is essentially hydrophobic, the reaction products are hydrophilic (Lee et al., 2012).

This study investigates the chemical mechanisms of OL ozonolysis and the resulting product distribution, assessed as a function of particle size using a variety of novel online physical and chemical analysis methodologies. The effect of relative humidity upon the (size-dependent) predominant reaction mechanism is also explored, and the resulting implications for the atmospheric processing of organic aerosol are considered.

\section{Experimental}

\subsection{Experimental design}

A schematic diagram of the experimental set-up for the ozonolysis of OL aerosol is shown in Fig. 1. The system comprised a gas handling and control system, an aerosol generator, ozone generator, humidifier (bubbler), and an aerosol flow tube (AFT), coupled to aerosol particle characterisation (SMPS - scanning mobility particle spectrometer - and ATOFMS - aerosol time-of-flight mass spectrometer) instruments, and monitors to measure ozone, temperature, and RH. The set-up was designed so the ozonolysis of OL aerosol could be studied under well-defined conditions within the AFT.

The AFT reactor consisted of a cylindrical tube formed from Pyrex (internal diameter of $10 \mathrm{~cm}$, length of $100 \mathrm{~cm}$ ), which was sealed with aluminium flanges. The reactor was held in a vertical orientation within a supporting frame. Gas inlets and outlets were coupled to the flanges to allow for the entrance and exit of the gas and aerosol streams. The ozone monitor, SMPS, and ATOFMS sampling outlets were located immediately downstream of the AFT. Typical gas flows entering the AFT were as follows: OL aerosol containing flow (1.0 slm in synthetic air), ozone containing dry synthetic air $(0.5 \mathrm{slm})$, and dry or humidified synthetic air $(2.0 \mathrm{slm})$, resulting in a total flow rate of $3.5 \mathrm{slm}$ which corresponded to 


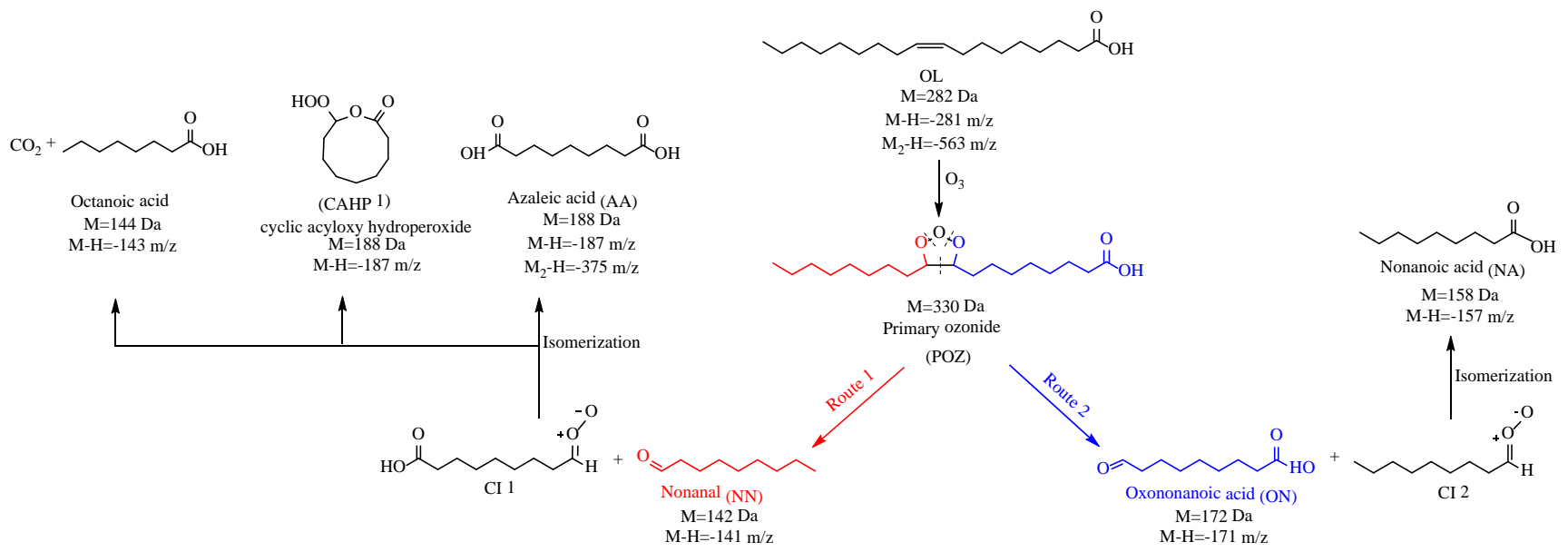

Scheme 1. Initial steps and primary products of oleic acid (OL) oxidation by $\mathrm{O}_{3}$.

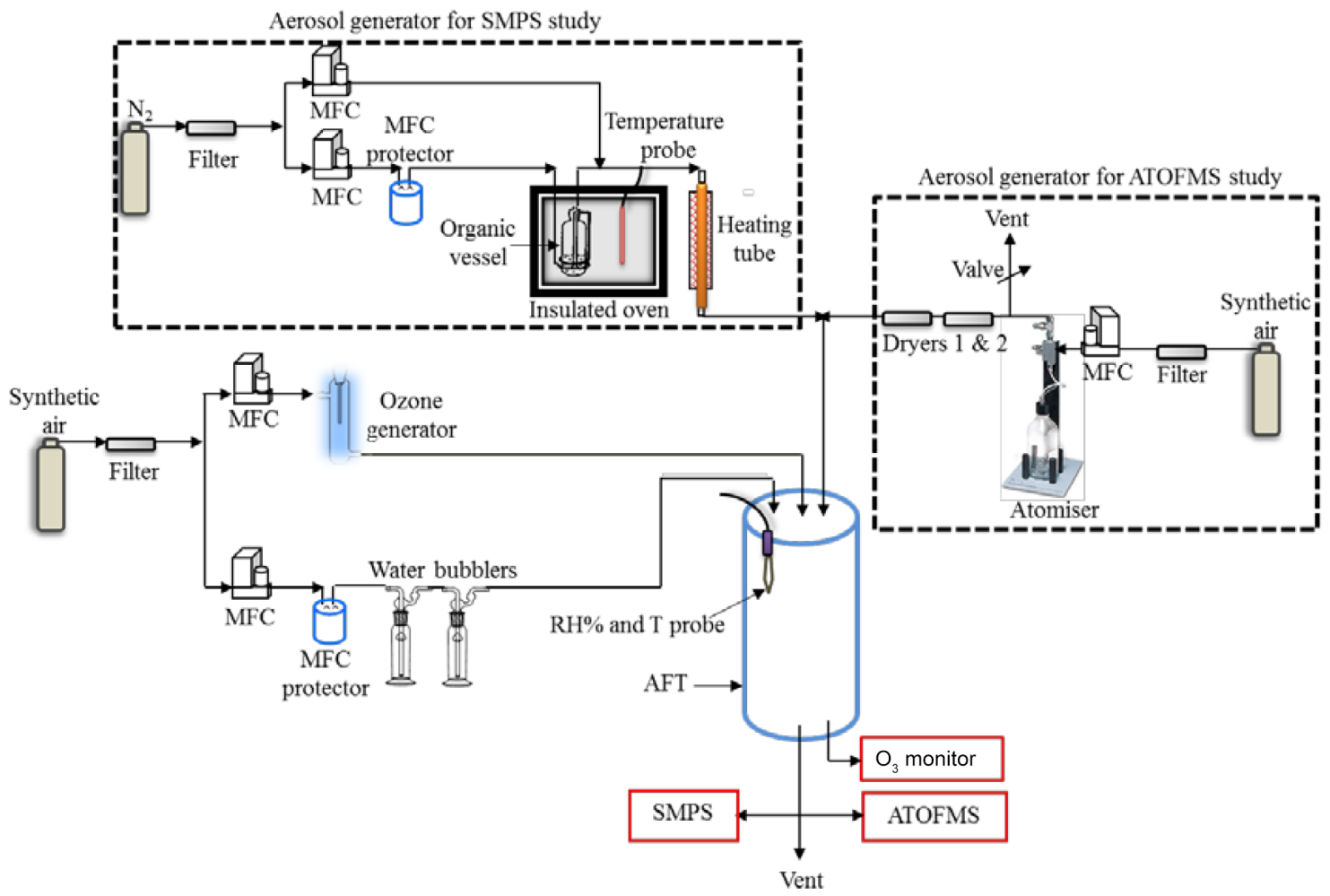

Figure 1. The experimental set-up for the study of the heterogeneous oxidation of OL aerosol.

a (plug flow) residence time of $135 \mathrm{~s}$. In some experiments a nitrogen flow was used to generate the aerosol (via homogeneous nucleation of OL); in these cases a small flow of oxygen was added to ensure the air composition within the AFT had an atmospheric $\mathrm{N}_{2}: \mathrm{O}_{2}$ ratio. Constant gas flows were achieved using calibrated mass flow controllers. The Reynolds number for the AFT was 13.1 and hence flow within the reactor was predicted to lie firmly within the lam- inar regime after an initial flow development length (estimated at $4.6 \mathrm{~cm}$, i.e. $<5 \%$ of the total length).

To ensure that particle processing was dominated by the AFT section of the set-up, the additional residence time within the sampling and characterisation stages was assessed. The calculated residence time of the aerosol in the sampling tubes (<2 s) and SMPS (<1 s; von Hessberg et al., 2009) was negligible. Within the ATOFMS the residence time is very small, and the low operating pressures within the ATOFMS 
( $\sim 10^{-7}$ Torr) minimise interactions between ozone and particles, and hence particle reactivity is considered to be terminated at the very early stages of the ATOFMS sampling nozzle.

A hygrometer probe positioned inside the AFT was used to monitor RH and temperature. Experiments were typically run under both dry and humidified conditions, which corresponded to measured relative humidities of $0.5 \pm 0.02$ and $65.0 \pm 0.2 \%$, respectively.

Each experiment was run back to back with and without the presence of ozone, with all other conditions remaining identical, to allow measurement of both the initial OL particles before ozonolysis and the resulting aerosol post ozonolysis. Measurements were conducted once the aerosol concentration, size distribution, and ozone concentration had stabilised. The system was flushed between runs to prevent contamination from prior experiments.

\subsection{Scanning mobility particle sizer}

To follow changes in the OL particle size distribution due to ozonolysis, an SMPS system comprising an electrostatic classifier (TSI model 3080), neutraliser (TSI model 3076), long column differential mobility analyzer (LDMA; TSI model 3081), and condensation particle counter (CPC, 3022A) was used to monitor the aerosol size distribution. A particle density equal to that of pure OL $\left(0.891 \mathrm{~g} \mathrm{~cm}^{-3}\right)$ was applied to determine changes in the number, diameter, volume, and mass distribution of OL particles. Aerosols were monitored in the size range of $15.1-667 \mathrm{~nm}$, every $3 \mathrm{~min}$, before and after exposure to ozone. For each experimental setting, a minimum of 10 sizing scans were averaged.

\subsection{Aerosol time-of-flight mass spectrometer}

A detailed description of the ATOFMS is given elsewhere (Gard et al., 1997; Sullivan and Prather, 2005; Dall'Osto et al., 2006); briefly, the ATOFMS is an online single particle instrument which was applied here to measure the physical and chemical characteristics of OL aerosol before and after ozonolysis. The ATOFMS deployed in this study (TSI, model $3800-100$ ) sampled particles in the size range $100-3000 \mathrm{~nm}$. For analysis of individual particle composition, time-of-flight mass spectrometry (TOF-MS) was used with a laser $(266 \mathrm{~nm})$ desorption ionisation (LDI) source.

The ATOFMS sampled from the AFT at a flow rate of $0.3 \mathrm{slm}$. When an aerosol flow enters the ATOFMS it is directed through an expansion nozzle and skimmers during which particles are accelerated to a velocity characteristic of their aerodynamic size; the smaller the particle is, the higher the speed. Velocities of individual particles, hence aerodynamic size, are measured via scattered light from two CW timing lasers $(532 \mathrm{~nm})$ positioned a known distance apart. The particle velocity determines the timing of the subsequent LDI pulse to allow for interaction between particles and LDI.
Once ionised, the molecular fragments from the particle are directed to both positive and negative polarity time-of-flight mass spectrometers.

The detection of particles within the ATOFMS is reliant upon the LDI pulse generating ions, requiring the particle to have sufficient absorption properties at $266 \mathrm{~nm}$. We found that the interaction between the LDI and both OL and its ozonolysis products produced only negligible ions, failing to meet the detection criteria of ATOFMS. To increase the absorption properties of the particles, the dye nile blue sulfate (NBS) was introduced into the OL particles. NBS effectively absorbs light at the lasing wavelength of the LDI laser with absorption peaks occurring at 624,325 , and $276 \mathrm{~nm}$, and therefore its introduction into the aerosol provides a methodology for efficient ionisation. NBS was also separately introduced into calibration particles formed from each of the primary products of OL ozonolysis (see Results section).

Although the ATOFMS response is matrix-sensitive and may not directly reflect the quantitative composition of the measured aerosol (Gross et al., 2000; Fergenson et al., 2001; Bhave et al., 2002; Sullivan and Prather, 2005; Allen et al., 2006; Dall'Osto et al., 2006), relative peak intensities can be meaningful when particle constitution within a measured sample has not changed considerably during a given investigation (Gard et al., 1998; Finlayson-Pitts and Pitts, 2000). In this sense, the use of ATOFMS as a semi-quantifiable approach for the analysis of aged OL particles as a function of particle size is justifiable because individual laboratory based particles studied under experimentally controlled conditions are far less complex - and variable - than atmospheric aerosol (Allen, 2004). Moreover, ATOFMS information on particle number and the abundance of different species by particle size is possible with high time resolution (Dall'Osto and Harrison, 2012). Most importantly, the relative signal intensities arising from the major oxidation products of the OL- $\mathrm{O}_{3}$ heterogeneous reaction were studied using individual authenticated standards, the analysis of which was used to calibrate signals arising from reacted oleic acid particles. The minimal residence time of the ATOFMS instrument (compared with, for example, drift-tube techniques) minimises the scope for within-detector ion-molecule chemistry to contribute to the observed signals; further confidence in this regard is achieved through the focus upon changes in signal upon addition of the chromophore and as a function of chemical reaction conditions (in comparison with a focus upon direct spectra).

The ATOFMS particle sizing was calibrated with standardised polystyrene latex spheres (PSL; calibrated diameters of $0.2,0.3,0.4,0.56,0.7,1.3,2$, and $2.5 \mu \mathrm{m}$ ). Dilute PSL suspensions were prepared in deionised water and nebulised using a constant output atomiser and diffusion dryer. Analysis of the measured velocity of the nebulised PSL particles as a function of their known particle sizes provided a calibration curve for the ATOFMS particle sizing. 
The mass scale of the ATOFMS was calibrated through nebulisation of two multi-element commercial standards (see Chemicals and Reagents, below) and further standards prepared for this study reflecting the principal products of the OL ozonolysis system: OL, AA, NN, NA, and 4-ON together with NBS (added chromophore). The obtained time of flight of the resulting ions in each case was related to the corresponding expected $\mathrm{m} / \mathrm{z}$ values. This approach allowed for the ATOFMS response to be directly calibrated up to $563 \mathrm{Da}$. $\mathrm{m} / \mathrm{z}$ values reported here beyond this limit have been calibrated using the molecular masses for those higher molecular weight products for which identities have been proposed. To assess the relative sensitivity of the ATOFMS towards OL, NN, AA, NA, and 4-ON, a standard mixture solution containing OL, NN, AA, NA, and 4-ON at equimolar concentrations, plus traces of the laser dye, NBS, was prepared in methanol and aerosolised using liquid atomisation. The ATOFMS datasets were all processed using MS Analyse and Microsoft Access software.

\subsection{Generation and measurement of OL aerosol and ozone}

Ozone was generated by flowing $0.5 \mathrm{slm}$ of synthetic air through a quartz photolysis tube illuminated by a mercury UV pen-ray lamp. The ozone concentration was monitored downstream of the AFT using an ozone monitor (2B Technologies, model 205). The ozone mixing ratio was $20 \mathrm{ppm}$. An elevated $\mathrm{O}_{3}$ level allows use of short contact times in the AFT and corresponds to an integrated exposure approximately equivalent to about 1 day in ambient air (if potential within-particle diffusion limitations may be neglected).

Two approaches were used to generate OL aerosol. For the physical characterisation of OL aerosol using the SMPS, liquid OL particles were generated by homogenous nucleation of pure OL vapour. The low-volatile OL liquid was heated in a Pyrex vessel, in an insulated and temperaturecontrolled oven $\left(120 \pm 0.5^{\circ} \mathrm{C}\right)$, to create OL vapour. To aid evaporation, $0.5 \mathrm{slm}$ of $\mathrm{N}_{2}$ gas was bubbled through the liquid OL. Subsequently, the vapour underwent homogeneous nucleation into OL aerosol particles accelerated by the introduction of a $0.5 \mathrm{slm}$ flow of $\mathrm{N}_{2}$ gas at ambient temperature. The resulting aerosol stream was passed through a reheating tube $\left(200^{\circ} \mathrm{C}\right)$ to homogenise the aerosol and narrow the resulting particle size distribution. All steps in the procedure were kept at temperatures significantly below the boiling point of $\mathrm{OL}\left(360^{\circ} \mathrm{C}\right)$ to prevent pyrolysis. Overall, these operating conditions generated OL aerosols with a geometric standard deviation $\sigma_{\mathrm{g}}$ of 1.2 , a mass median diameter close to $400 \mathrm{~nm}$, and a total particle number concentration of $\sim 10^{6} \mathrm{~cm}^{-3}$.

For the chemical product study of OL aerosol using the ATOFMS, a different method for generating OL aerosol was required as a consequence of the necessity of doping the aerosol with NBS dye (see discussion above). NBS was added at a low concentration $\left(5 \times 10^{-5} \mathrm{M}\right)$ to liquid OL and the mixture made up into $0.15 \mathrm{M}$ solutions of $\mathrm{OL}$ in methanol. Subsequently, a constant output atomiser (TSI, model 3076) was used to generate a polydisperse aerosol ensemble from the solution. The atomiser requires a constant flow rate of $3.0 \mathrm{slm}$ for operation. Of this aerosolcontaining flow, $1.0 \mathrm{slm}$ was directed into the AFT after it passed through a series of two silica gel diffusion dryers (TSI, model 3062) for the removal of methanol prior to entry to the AFT, while the remaining flow was vented. Under the experimental conditions of this study, methanol is expected to fully evaporate and indeed no methanol signal was detected in any of the ATOFMS mass spectra. Generation of the other aerosols containing NBS (i.e. calibration standards) was performed in the same manner.

\subsection{Chemicals and reagents}

Liquid OL (purity > 99.0\%), solid crystalline AA (98\%), liquid NN (95\%), liquid NA (96\%), and liquid 4-ON (95\%) were purchased from Sigma-Aldrich and used as supplied. For ATOFMS mass calibration, multi-element standard solutions were used: standard A $\left(900 \mu \mathrm{g} \mathrm{mL}^{-1}: \mathrm{Ba}, \mathrm{Pb}, \mathrm{Li}, \mathrm{K}\right.$, $\mathrm{Na}$, and $\mathrm{V}$ in $\left.5 \% \mathrm{HNO}_{3}\right)$ and standard $\mathrm{B}\left(900 \mu \mathrm{gLL}^{-1}\right.$ : $\mathrm{Ag}$ and $\mathrm{Mo}$ in $5 \% \mathrm{HNO}_{3}$ ) obtained from TSI Inc. The size calibration of the ATOFMS used PSL (diameter range: 0.1 to $2.5 \mu \mathrm{m}$, Duke Scientific). The cationic laser dye, bis[5amino-9-(diethylamino)benzo[a]phenoxazin-7-ium] sulfate (NBS), used to modify the spectroscopic properties of OL particles, and laboratory-grade methanol were obtained from Fisher Scientific. Synthetic air and nitrogen-free oxygen $\left(\mathrm{N}_{2}\right.$; 99.9\% stated purity) were supplied by the manufacturer BOC and purified by passing through charcoal traps (Grace Discovery Science, efficiency $<20 \mathrm{ppb}$ ) to remove trace hydrocarbon impurities. Traces of water were removed from the gas lines using a trap (Sigma-Aldrich, Molecular Sieve 5A Moisture Trap).

\section{Results}

\subsection{Effect of ozonolysis on particle size}

The size distributions of ozonolysed and non-ozonolysed OL particles, under both dry and humidified conditions, are shown in panels (a) and (b) in Fig. 2. To aid comparison, the wet and dry results are combined and normalised to the peak signal of the non-processed particle in Fig. 2c. It can be clearly observed that OL particles lose mass upon oxidation under both dry and humidified conditions. The modal diameter decreases from $400 \pm 14$ to $346 \pm 13 \mathrm{~nm}$ and from $372 \pm 13$ to $322 \pm 12 \mathrm{~nm}$ under the dry and humidified conditions, respectively, corresponding to a total mass loss (estimated from the SMPS) of $32.5 \pm 5.3$ and $26.3 \pm 2.5 \%$, respectively. Although the observed mass loss upon oxidation is consistent with previously reported qualitative and quanti- 

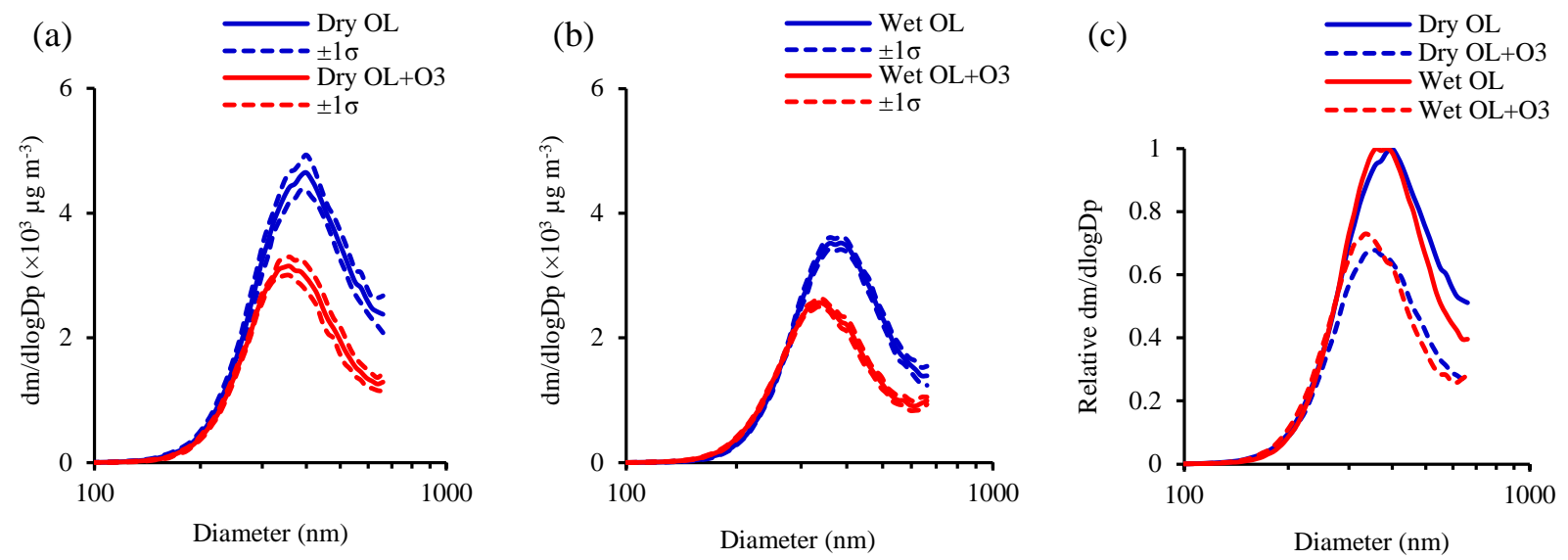

Figure 2. Particle mass size distributions for (a) pure and oxidised OL aerosol under dry condition (RH $0 . \pm 0.02 \%$ ), (b) pure and oxidised OL aerosol under wet condition (RH $65.0 \pm 0.2 \%$ ), and (c) normalised particle size distribution of pure and oxidised OL aerosol under dry and wet conditions. Each curve represents the mean average of 10 measurements with accompanying standard deviation $(\sigma)$.

tative observations (Morris et al., 2002; Katrib et al., 2004; Katrib et al., 2005b; Dennis-Smither et al., 2012b; Lee et al., 2012), in view of the measured uncertainties the difference between the two experiments, under different RH conditions, is statistically insignificant. The lack of hygroscopic growth of the initial $\mathrm{OL}$ aerosol is consistent with the observations of Dennis-Smither et al. (2012a) and Hung et al. (2005).

The decrease in the mobility diameter of OL particles upon oxidation is likely due to the formation of volatile products that partition from the particle to the gas phase. This is consistent with previous studies that have identified gas-phase products. In particular the highly volatile NN and the semivolatile NA products have been previously identified (Moise and Rudich, 2002; Smith et al., 2002; Thornberry and Abbatt, 2004; Vesna et al., 2009; Lee et al., 2012). The formation of low-volatility products, which remain in the particle phase and typically possess greater densities $(\rho)$ than OL $\left(\rho=0.891 \mathrm{~g} \mathrm{~cm}^{-3}\right)$, such as AA $\left(\rho=1.225 \mathrm{~g} \mathrm{~cm}^{-3}\right)$ and 9-ON $\left(\rho=1.019 \mathrm{~g} \mathrm{~cm}^{-3}\right)$, may also have an influence.

The fact that less mass loss was observed under humidified conditions than under dry conditions (although the difference was statistically insignificant) suggests that the presence of water might have an effect on the oxidation mechanism. Such a conclusion has been reported in the literature for similar oxidation conditions (Gallimore et al., 2011). It has been suggested that the presence of particle-phase water leads to different CI reactivity (i.e. an alternate CI fate), which results in the formation of less-volatile products (such as organic acid formation) and hence less particle mass loss (Gallimore et al., 2011). This is surprising because OL and its oxidation products, even though they are smaller and contain more hydrophilic chemical moieties (carboxylic acid and hydroxyl groups), have low solubility in water. Results from other experimental studies indicate that OL has mild hygroscopicity (Andrews and Larson, 1993; Kumar et al., 2003;
Vesna et al., 2008). Furthermore, thermodynamic modelling indicates that OL and ozonolysed OL particles show small but non-negligible hygroscopicity at RH $65 \%$ (Lee et al., 2012). It should be noted that hygroscopicity is defined by mass or diameter growth upon uptake of water referenced to the dry state. Since the molar mass and molar volume of water is much smaller than OL and its oxidation products, the molar ratio of water to OL or its oxidation products is much greater than the reported hygroscopicity would suggest. Dennis-Smither et al. (2012a, b) report a reduction in particle size with oxidation of OL and that hygroscopicity increases with oxidative aging. While Lee et al. (2012) observed no change to the reaction scheme of OL with increased humidity, Vesna et al. (2009) report changes in product yields.

\subsection{Chemical characterisation of OL and ozonolysed OL aerosol}

Particles leaving the AFT were sampled by the ATOFMS. Ionisation within the instrument leads to ions which enter two time-of-flight mass spectrometers. Both positive and negative mass spectra were recorded for all detected particles. The negative mass spectra show a greater abundance of peaks, which is expected based upon the predicted reaction pathways (see Scheme 1) because most OL oxidation products contain carboxylic acid and/or aldehyde moieties which are principally detected as deprotonated molecular ions [M$\mathrm{H}]^{-}$formed via proton abstraction. To allow easier interpretation and minimise fragmentation, the LDI laser fluence of the ATOFMS was kept very low (0.4-0.8 mJ per pulse) as compared to other studies (1.3-1.6 mJ; Silva and Prather, 2000; Dall'Osto and Harrison, 2012). Nevertheless, it should be noted that some fragmentation of ions in the ATOFMS system is expected and this can lead to difficulty in interpretation. 


\subsection{Mass spectrometric analysis of NBS and OL}

To probe for any influence of NBS on the chemistry of OL ozonolysis two preliminary tests were carried out. Firstly the mass spectra of NBS aerosol with and without $\mathrm{O}_{3}$ present were recorded (Fig. S1a). Secondly the mass spectrum of aerosol composed of NBS and OL without $\mathrm{O}_{3}$ was recorded (Fig. S1b). NBS displays three strong signals in the positive spectrum at $m / z+274$ and +308 assigned to the cationic dye fragments and +318 assigned for the non-fragmented dye cation. The two strong signals in the negative spectra at $m / z-96$ and -80 correspond, respectively, to the sulfate $\left(\mathrm{SO}_{4}^{2-}\right)$ and sulfite $\left(\mathrm{SO}_{3}^{2-}\right)$ ions of the dye. No changes in the NBS spectra were detected when NBS particles were exposed to ozone (Fig. S1a). When OL was added to NBS solution in the absence of ozone, the only additional peaks observed were the deprotonated mass signals from OL and the OL dimer. It should be noted that NBS peaks were always observed in all mass spectra shown henceforth. However, for the ease of the analysis, all NBS peaks are omitted from the presented mass spectra.

\subsection{Mass spectrometric analysis of OL oxidation products}

In order to quantify the products of OL ozonolysis the relationship between the mass spectral signal and the concentration needs to be quantified. Standards for OL, AA, NN, and NA were all commercially available. However, ON was not commercially available but its isomer $4-\mathrm{ON}$ was. The detection of ON via the ATOFMS is expected to be nearly identical to that of 4-ON. ON contains a carboxylic acid and an aldehyde group whereas 4-ON contains carboxylic acid and ketone groups. Both acids, derived from ON and 4-ON, are expected to exhibit a deprotonated carboxylate ion [M$\mathrm{H}]^{-}$and were detected in the negative ion mass spectrum at $m / z-171$. Standards for the high molecular weight oxidation products are not available commercially and are difficult to synthesise and hence were unavailable for this study.

Figure 3 shows the positive and negative mass spectra of the individual standards. Unreacted OL aerosol (282 Da) was seen as a deprotonated OL molecular ion at $m / z=-281$ and as a singly deprotonated dimer at $m / z-563$. The deprotonated molecular ions of AA (MW $=188 \mathrm{Da}), \mathrm{NA}(158 \mathrm{Da})$, $\mathrm{NN}(142 \mathrm{Da})$, and 4-ON (172 Da) are seen as major peaks at $m / z-187,-157,-141$, and -171 , respectively, while the singly deprotonated dimers of AA and NA were measured at $m / z-375$ and -315 , respectively. In the positive ion mass spectra of AA a signal at $m / z+155$ was attributed to the fraction of the molecule after the loss of an $\mathrm{HO}_{2}$ fragment [M$\left.\mathrm{HO}_{2}\right]^{+}$. The molecular ion peak measured at $m / z+113$ in the NA positive ion mass spectra was assigned to the molecular fragment of NA after the loss of $\mathrm{CO}_{2} \mathrm{H},\left[\mathrm{M}-\mathrm{CO}_{2} \mathrm{H}\right]^{+}$. It is important to note that the ATOFMS intensity for individual ions is dependent upon the total composition of the particle.
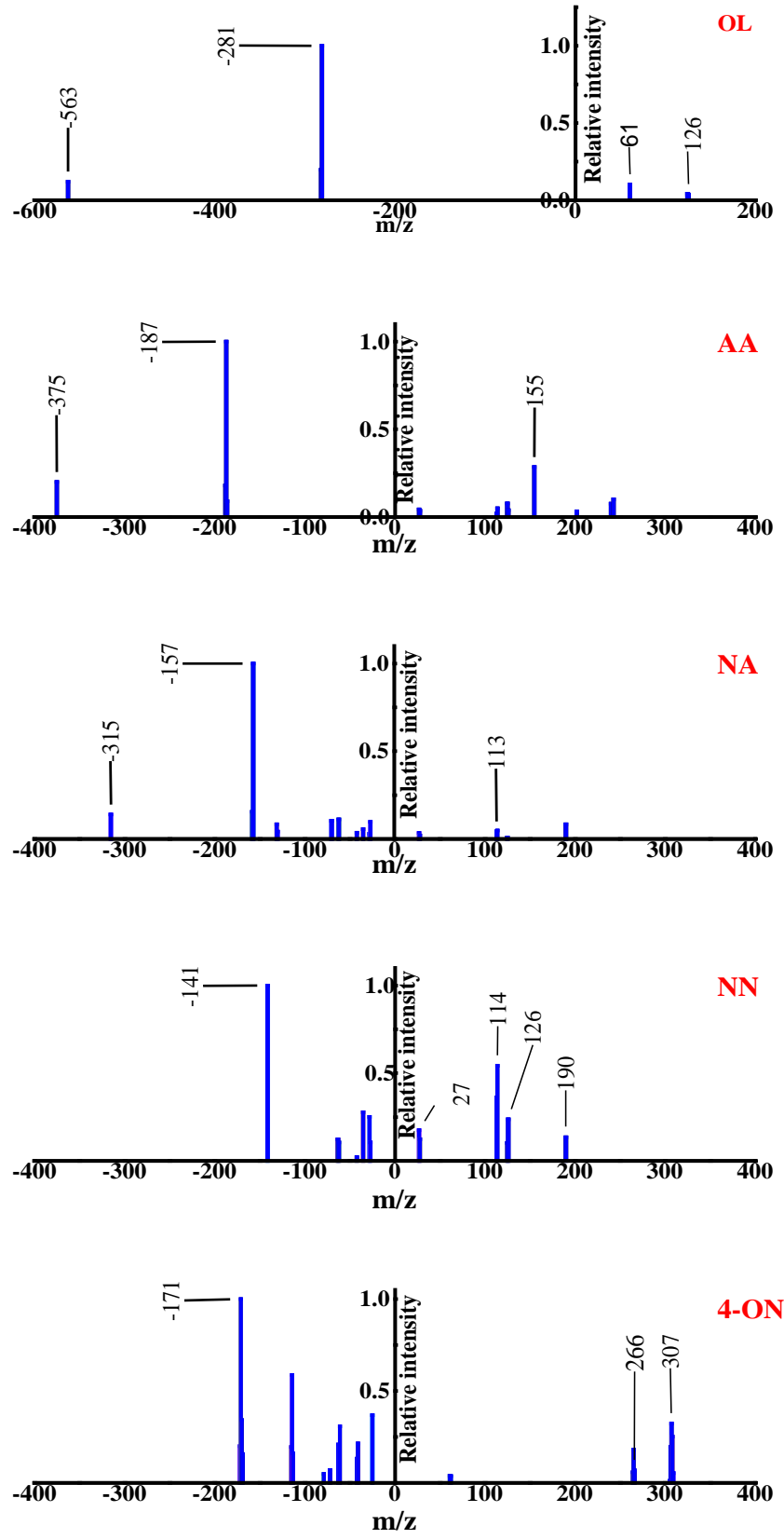

Figure 3. Positive and negative ion mass spectra of OL, AA, NA, $\mathrm{NN}$, and 4-ON. Each spectrum presented represents the average from 100 mass spectra.

To investigate ATOFMS sensitivity towards OL and the primary ozonolysis products, a solution containing an equimolar mixture of $\mathrm{OL}, \mathrm{AA}, \mathrm{NA}, \mathrm{NN}$, and 4-ON was examined under the same experimental conditions as the oxidation experiments. Figure 4 shows the results of the ATOFMS (relative) sensitivity to the deprotonated molecular ions of the five component mixture. An average spectrum comprised of 200 spectra was used for the analysis. It is evident that the 


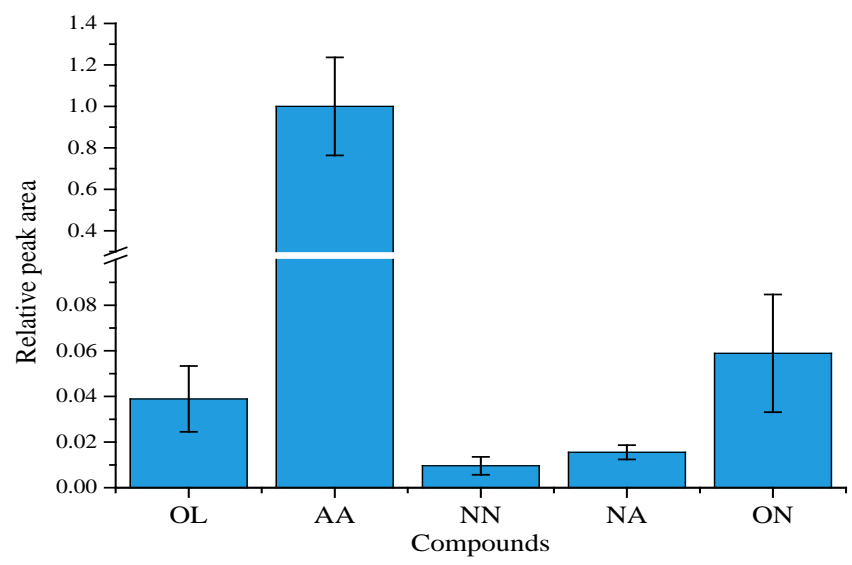

Figure 4. Relative peak area signals from aerosol particles generated from an equimolar mixture of OL, AA, NA, NN, and 4-ON. Peak areas are an average from 200 mass spectra.

ATOFMS sensitivity varies considerably between the different compounds.

The figure indicates that the signals observed for the five component mixture is in the following order: $\mathrm{AA}>>\mathrm{ON}$ $>\mathrm{OL}>\mathrm{NA}>\mathrm{NN}$. The much greater signal from AA compared to the other species can be partially understood because it is a dicarboxylic acid and thus has a greater possibility of being ionised to the carboxylate ion compared to the species containing only one carboxylic acid moiety. $\mathrm{ON}$ and OL have similar signals, which is expected since they both contain one carboxylic acid group. The signal from NN is the smallest probably because it only contains an aldehyde moiety, which is more difficult to ionise compared to carboxylic acids. Previous studies on NN detection using soft ionisation and ultra-high-resolution mass spectrometry also showed weak NN peaks in the mass spectra. The authors attribute this observation partly to the poor signal produced from aldehydes by the deployed techniques (Grimm et al., 2006; Hosny et al., 2013). The high volatility of NN will also lead to the partitioning from the aerosol to gas phase, thereby reducing the particle-phase concentration, although it is noted that this process will also happen in the processed oleic acid particles.

The relative peak areas of the five component mixture were converted into sensitivity correction factors (SCF) that allow for relative concentrations of these components to be estimated within the ozonolysed OL particles. It should be noted that this approach - as in many other analytical approaches - is not sensitive to any matrix effect of ozonolysed OL particles which might have an impact of suppressing or enhancing ATOFMS signals of individual components. To minimise possible matrix complications, the relative peak intensities of the individual components within each measured sample were used to describe the component distribution of the chemically aged OL polydisperse aerosol. As mentioned in Sect. 2.3, satisfactory ATOFMS measurement of the aged
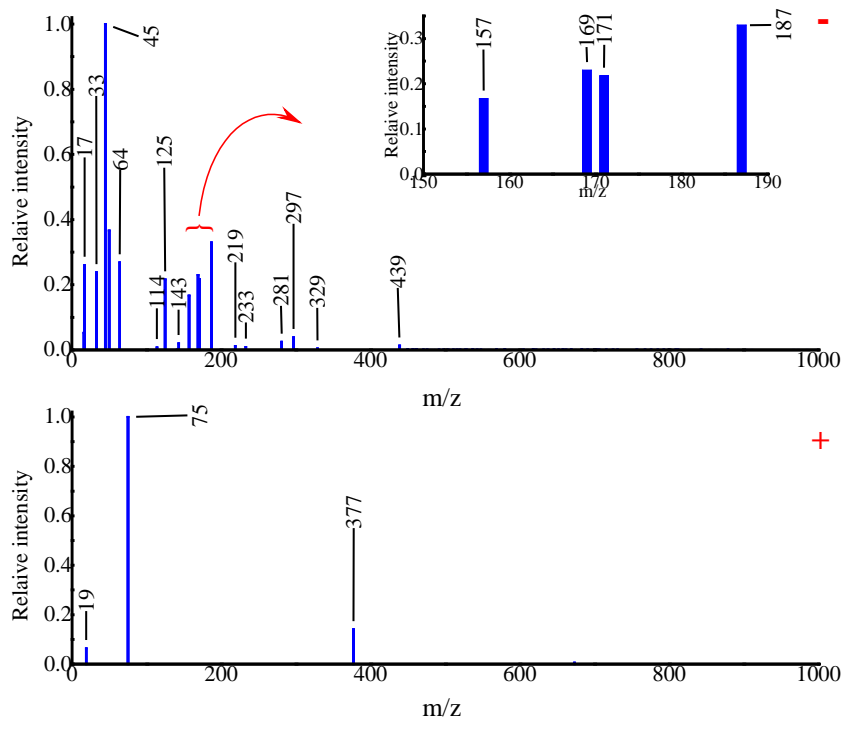

Figure 5. Averaged ATOFMS negative and positive ion mass spectra for small processed OL particles $\left(D_{\mathrm{p}}<0.3 \mu \mathrm{m}\right)$.

OL particles required improving the efficiency of the LDI by optically modifying the matrix of OL particles using added NBS laser dye. This modification resulted in a substantial enhancement in ATOFMS detection of particles apparently by maximising the absorption efficiency of the pulsed laser by the particles.

\subsection{Mass spectrometric analysis of aged OL particles}

The size-binned ATOFMS data show distinct differences in composition between small particles $\left(D_{\mathrm{p}}<0.3 \mu \mathrm{m}\right)$ and large particles $\left(D_{\mathrm{p}}>0.3 \mu \mathrm{m}\right)$. Small particles are characterised by the presence of compounds with molecular weights lower than the parent OL molecules $(m / z<282)$, whereas large particles are characterised by significant formation of higher molecular weight (HMW) compounds $(m / z>282)$. Smith et al. (2002) measured ozone uptake by OL particles as a function of particle size. They found that the effective uptake coefficient of ozone decreased with increasing particle size, concluding that this resulted from the reaction being limited by the diffusion of OL within the particle. Under such conditions, reactions between intermediate products and OL become important, hence leading to the formation of higher molecular weight species (Hung et al., 2005, 2007; Katrib et al., 2004). Reactions between ozonolysis products and Criegee intermediates also lead to high molecular weight products when the supply of ozone is limited (Reynolds et al., 2006; Zahardis et al., 2006). Our interpretation of the mass spectral information gained from the ATOFMS appears in Table 1. 
Table 1. A summary of proposed components and possible propagator combinations contributing to the observed mass spectral peaks corresponding to 44 oxidation products of the $\mathrm{OL}-\mathrm{O}_{3}$ system.

\begin{tabular}{|c|c|c|c|c|c|c|c|c|c|c|c|}
\hline \multirow[b]{2}{*}{ MW } & \multicolumn{2}{|c|}{ MS signature } & \multicolumn{8}{|c|}{ No. of combined components } & \multirow[b]{2}{*}{$\begin{array}{r}\text { Dehydration } \\
\left(-\mathrm{nH}_{2} \mathrm{O}\right)\end{array}$} \\
\hline & $-m / z$ & $+m / z$ & NN & OcA & $\begin{array}{r}\text { AA or } \\
\text { CI1 }\end{array}$ & ON & $\begin{array}{r}\text { NA or } \\
\mathrm{CI} 2\end{array}$ & $\begin{array}{r}\text { Ox } 1 \text { or } \\
\text { Ox } 2\end{array}$ & Ox3 & $\mathrm{OL}$ & \\
\hline 142 & 141 & & 1 & & & & & & & & \\
\hline 144 & 143 & & & 1 & & & & & & & \\
\hline 158 & 157 & & & & & & 1 & & & & \\
\hline 170 & 169 & & & & 1 & & & & & & 1 \\
\hline 172 & 171 & & & & & 1 & & & & & \\
\hline 188 & 187 & & & & 1 & & & & & & \\
\hline 298 & 297 & & & & & & & 1 & & & \\
\hline 314 & 313 & & & 1 & 1 & & & & & & \\
\hline 328 & 327 & & & & & & & 1 & & & \\
\hline 342 & 341 & & & & 1 & 1 & & & & & \\
\hline 422 & 421 & $377^{1}$ & & & & & 1 & & & 1 & 1 \\
\hline 440 & 439 & $423^{3}$ & & & & & 1 & & & 1 & 0 \\
\hline \multirow[t]{3}{*}{528} & 527 & $466^{1,3}$ & & & 3 & & & & & & 3 \\
\hline & & $483^{1}$ & & & & & & & & & \\
\hline & & $547^{3}$ & & & & & & & & & \\
\hline 644 & 643 & $599^{1}$ & & & & & 2 & & 1 & & 0 \\
\hline 656 & 655 & & & & 2 & & 2 & & & & 2 \\
\hline 768 & 767 & & & & 1 & & 2 & & & 1 & 1 \\
\hline 786 & 785 & $753^{2}$ & & & 1 & & 2 & & & 1 & 0 \\
\hline \multirow[t]{2}{*}{810} & 809 & $793^{3}$ & & & 2 & 1 & 2 & & & & 3 \\
\hline & & $777^{2}$ & & & & & & & & & \\
\hline 844 & 843 & $811^{2}$ & & & 3 & & 2 & & & & 2 \\
\hline \multirow[t]{2}{*}{864} & 863 & $819^{1}$ & & & 2 & 1 & 2 & & & & 0 \\
\hline & & $831^{2}$ & & & & & & & & & \\
\hline 880 & 879 & & & & 3 & & 2 & & & & 0 \\
\hline 894 & 893 & $861^{2}$ & & & 3 & 1 & 1 & & & & 0 \\
\hline 950 & 949 & $917^{2}$ & & & 3 & & 1 & & & 1 & 3 \\
\hline 968 & 967 & $935^{2}$ & & & 3 & & 1 & & & 1 & 2 \\
\hline 974 & 973 & & & & 2 & & 2 & & & 1 & 0 \\
\hline 986 & 985 & $953^{2}$ & & & 3 & & 1 & & & 1 & 1 \\
\hline 1002 & 1001 & & & & 3 & & 3 & & & & 2 \\
\hline 1020 & 1019 & $1003^{3}$ & & & 3 & & 1 & 1 & & & 0 \\
\hline 1026 & 1025 & & & & 4 & & & & 1 & & 3 \\
\hline 1038 & 1037 & $1005^{2}$ & & & 3 & & 3 & & & & 0 \\
\hline 1051 & 1050 & $1070^{4}$ & & & 4 & & 2 & & & & 1 \\
\hline \multirow[t]{2}{*}{1068} & 1067 & $1023^{1}$ & & & 4 & & 2 & & & & 0 \\
\hline & & $1106^{4}$ & & & & & & & & & \\
\hline 1080 & 1079 & & & & 4 & & & & 1 & & 0 \\
\hline 1162 & 1161 & $1112^{2,3}$ & & & 3 & & 2 & & & 1 & 0 \\
\hline 1178 & 1177 & & & & 3 & & 4 & & & & 1 \\
\hline 1190 & 1189 & & & & 4 & & 1 & 1 & & & 1 \\
\hline 1196 & 1195 & & & & 3 & & 4 & & & & 0 \\
\hline 1208 & 1207 & & & & 4 & & 1 & 1 & & & 0 \\
\hline 1214 & 1213 & & & & 5 & & & & 1 & & 3 \\
\hline 1292 & 1291 & & & & 3 & 1 & & & 1 & 1 & 3 \\
\hline 1310 & 1309 & & & & 3 & 1 & & & 1 & 1 & 2 \\
\hline 1346 & 1345 & & & & 3 & 1 & & & 1 & 1 & 0 \\
\hline 1438 & 1437 & & & & 6 & & & & 1 & & 1 \\
\hline 1524 & & $1458^{2}$ & & & 3 & & 4 & & 1 & & 0 \\
\hline
\end{tabular}

${ }^{1} \mathrm{M}-\mathrm{CO}_{2} \mathrm{H} .{ }^{2} \mathrm{M}-\mathrm{HO}_{2} \cdot{ }^{3} \mathrm{M}-\mathrm{OH} .{ }^{4} \mathrm{M}+\mathrm{H}_{3} \mathrm{O}$. 


\subsection{Mechanisms and mass spectrometric analysis of small particles}

The mass spectrum of small oxidised OL particles (average of 300 spectra) is shown in Fig. 5. In addition to the parent OL signal measured at $m / z-281$, three of the primary ozonolysis products (AA, ON, and NA) were observed at $m / z-187,-171$, and -157 , respectively. Peaks measured at $m / z=-143,-329$, and -439 could be indicative of OcA (144 Da), the POZ (see Scheme 1), and the secondary reaction product of CI2 with OL (Reaction R1), respectively. The unidentified mass spectrum peaks are likely due to fragments (daughter ion peaks) or aggregates of ions. No useful insights were gained from the positive mass spectrum.

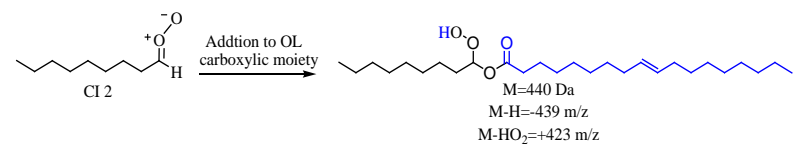

(R1)

\subsection{Mechanisms and mass spectrometric analysis of large size particles}

The three frames, a, b, and c, in Fig. 6 show negative and positive ion mass spectra of large $\left(D_{\mathrm{p}}>0.3 \mu \mathrm{m}\right)$ aged OL particles (average of 700 spectra). The negative ion mass spectrum is more complex but compatible with the hypothesis of secondary chemistry and the formation of HMW products. Generally, the spectrum demonstrates a strong peak of unreacted parent OL at $m / z-281$ and the appearance of the major oxidation products of ozone exposure. All four primary products (AA, ON, NA, and NN) are found to be in the particle phase including the highly volatile $\mathrm{NN}$, which was not detected in the small particles. The presence of $\mathrm{NN}$ in large particles is consistent with the observations of Dennis-Smithers et al., who studied supermicron-sized particles (Dennis-Smither et al., 2012b). The signals of AA and OcA, which form through the molecular rearrangement of CI1, were not detected in the larger particles, which might reveal that isomerisation is predominant in smaller particles and that it is the only formation source for these products. Both negative and positive average mass spectra are characterized by the presence of HMW products presumably formed by secondary association reactions of primary reaction products.

Previous studies have reported evidence of secondary chemistry occurring within the ozonolysis of OL particles (Katrib et al., 2004; Hearn et al., 2005; Ziemann, 2005; Reynolds et al., 2006; Zahardis et al., 2006; Zahardis and Petrucci, 2007; Lee et al., 2012; Hosny et al., 2013). The presence of the liquid condensed-phase substrate for the CIs minimizes their molecular rearrangement (Katrib et al., 2004) via a solvent cage effect (Park et al., 2006) and maximises their lifetimes. Therefore, reaction probability of
CIs with their corresponding carbonyl compounds to form secondary ozonide (SOZ) or with the alkene functionality becomes more significant (Neeb et al., 1998; Moise and Rudich, 2002; Zahardis et al., 2005).

Table 1 proposes molecular structures for the observed HMW mass spectral signals based upon polymerisation mechanisms previously proposed in the literature (Smith et al., 2002; Hearn and Smith, 2004; Katrib et al., 2004; Hung et al., 2005; Zahardis et al., 2005, 2006; Reynolds et al., 2006; Hung and Ariya, 2007; Zahardis and Petrucci, 2007). For instance, the peak at $m / z-297$ can be assigned for two isomeric compounds, 9-oxooctadecanoic acid (Ox1) or 10oxooctadecanoic acid (Ox2), depending on the type of the $\mathrm{CI}$ formed and the geometry of the CI addition across the double bond of $\mathrm{OL}$ to form the $\mathrm{C}_{27}$ peroxide which can cleave to yield the primary products ON or NN. Similarly, the detected signal at $m / z-327$ is determined as a reaction product between the OL double bond and CI1 to form 9-oxooctadecanedioic acid (Ox3). Scheme 2 illustrates a proposed mechanism and product structures formed as a result of the reaction between CI1 and the alkene functionality of OL. The experimental and modelling studies by Wang et al. have shown that the addition of CIs across the double bond of OL is the dominant loss route of CIs in OL-O $\mathrm{O}_{3}$ heterogeneous reaction system (Wang et al., 2016). We note that other reactions may also contribute to the observed products - for example, fates of the OL dimer - which these experiments cannot definitively constrain.

The presence of peaks correspond to Ox1 or Ox 2 in the OL- $\mathrm{O}_{3}$ heterogeneous reaction has been reported previously (Hearn and Smith, 2004; Zahardis et al., 2006; Hung and Ariya, 2007) while the reaction mechanism and product structures were first hypothesised by Katrib and co-workers (Katrib et al., 2004).

The existence of the carboxylic acid functionality in the oxidation products offers reaction sites for other CIs. The measured negative ion peaks at $m / z-1019,-1189$, and -1207 provide more evidence of the incorporation of Ox 1 or Ox2 as linear polymerisation propagators. However, the ion peak measured at $m / z-644$ is consistent with the formation of the ozonolysis product resulted from the reaction of two ions of CI1 and the two carboxylic moiety of one molecule of Ox.

The addition of CI2 terminates the polymerisation reaction as the $-\mathrm{CH}_{3}$ group cannot react further (Hung et al., 2005). The major HMW products ions at $m / z-1025,-1079$, $-1214,-1292,-1310,-1346,-1438$, and -1524 may also correspond to polymerisation products of Ox3 joined with other propagators. Products related to the secondary reaction of $\mathrm{ON}$ are also observed in a number of peaks. The negative ion at $m / z-341$ is most likely due to the combination of ON and CI1 to form AAHP (azelaic acid hydroperoxide) with a loss of one molecule of water. Although the same combination can lead to the formation of the SOZ, in such an arrangement a water molecule cannot be lost. The in situ 
(a)
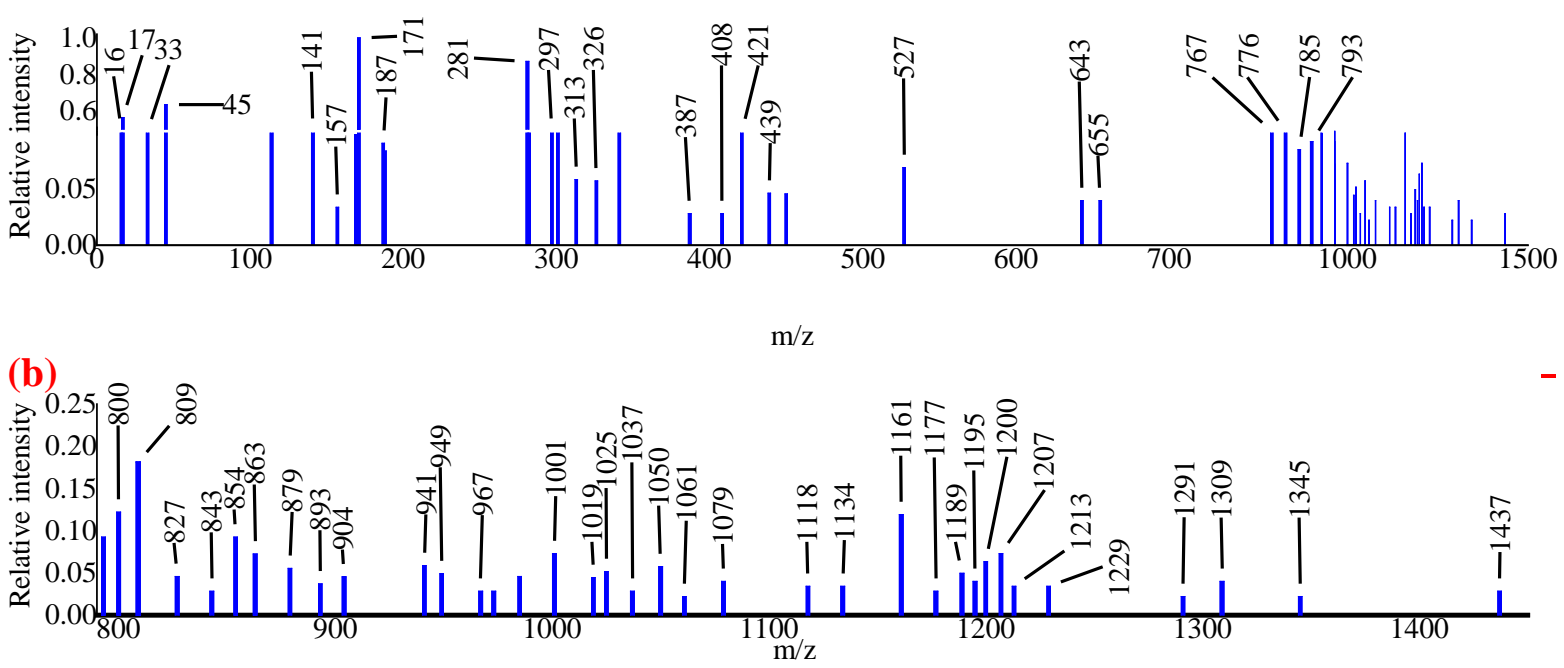

(c)

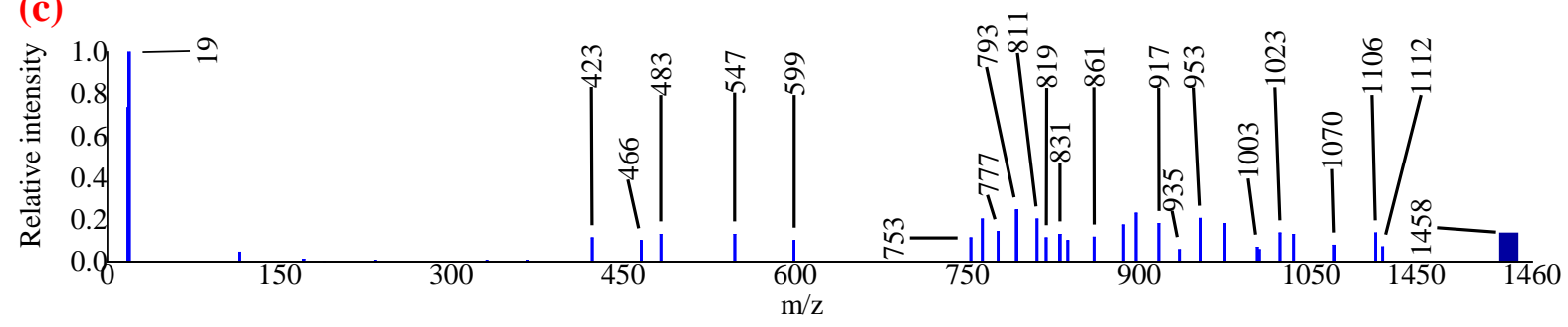

Figure 6. Average mass spectra of dry aged OL particles $\left(D_{\mathrm{p}}>0.3 \mu \mathrm{m}\right)$ : (a) negative ion MS; (b) zoom in plot of figure; (a) and (c) positive ion MS.

dehydration of AAHP was first observed and described by Zahardis and co-workers (Zahardis et al., 2006). The resultant proposed structure suggests possible additional moieties linking from molecule ends, the aldehyde and carboxylic acid groups, thereby growing into a HMW linear polymer. Scheme 3 shows the overall reaction. However, the intermediate association complexes are unlikely to be detected in reality, with conversion to the $\mathrm{M}-\mathrm{H}=341$ product and elimination of water proceeding as a concerted reaction.

\subsection{Particle composition as a function of particle size}

The ATOFMS technique allows for particle composition data to be collected as a function of particle size, thereby permitting the size dependence of the chemical aging of aerosols to be determined. This section investigates how the composition of aged OL particles changes, under dry and humidified conditions, as a function of particle size. The analysis only investigates the following compounds, which have clear MS peaks: OL, NN, AA, ON, NA, and HMW compounds $(m / z>282)$. The conversion from measured peak area to molar concentration is achieved using the SCF. Since an accurate SCF for the HMW compounds is difficult to determine due to the lack of standard laboratory calibrants, an upper limit value for the HMW SCF was estimated using a mass balance approach. In particular, the ratio between the OL signal to the total peak signals of the four primary oxidation products (AA, NN, NA, and $\mathrm{ON}$ ) was used to estimate the ratio between unreacted $\mathrm{OL}$ and the products. The obtained ratio of each product was corrected using the SCF to estimate the absolute molar ratio and hence the composition of the primary products in the particles. The reduction in the molar ratio between the four products and unreacted OL was used to estimate the SCF for the HMW (1 mole of OL produces 2 moles of the primary products; Scheme 1).

\subsection{Composition of aged OL particles under dry conditions}

Figure 7 provides the compositional analysis, by applying SCFs to the raw ATOFMS data, of 1000 aged OL particles that were ozonolysed under dry conditions. The sizedependent composition is given in Fig. 7a and the average composition of the aged OL polydisperse aerosol is shown in Fig. 7b. The average composition was achieved by taking the mean of all mass fractions analysed regardless of size; 


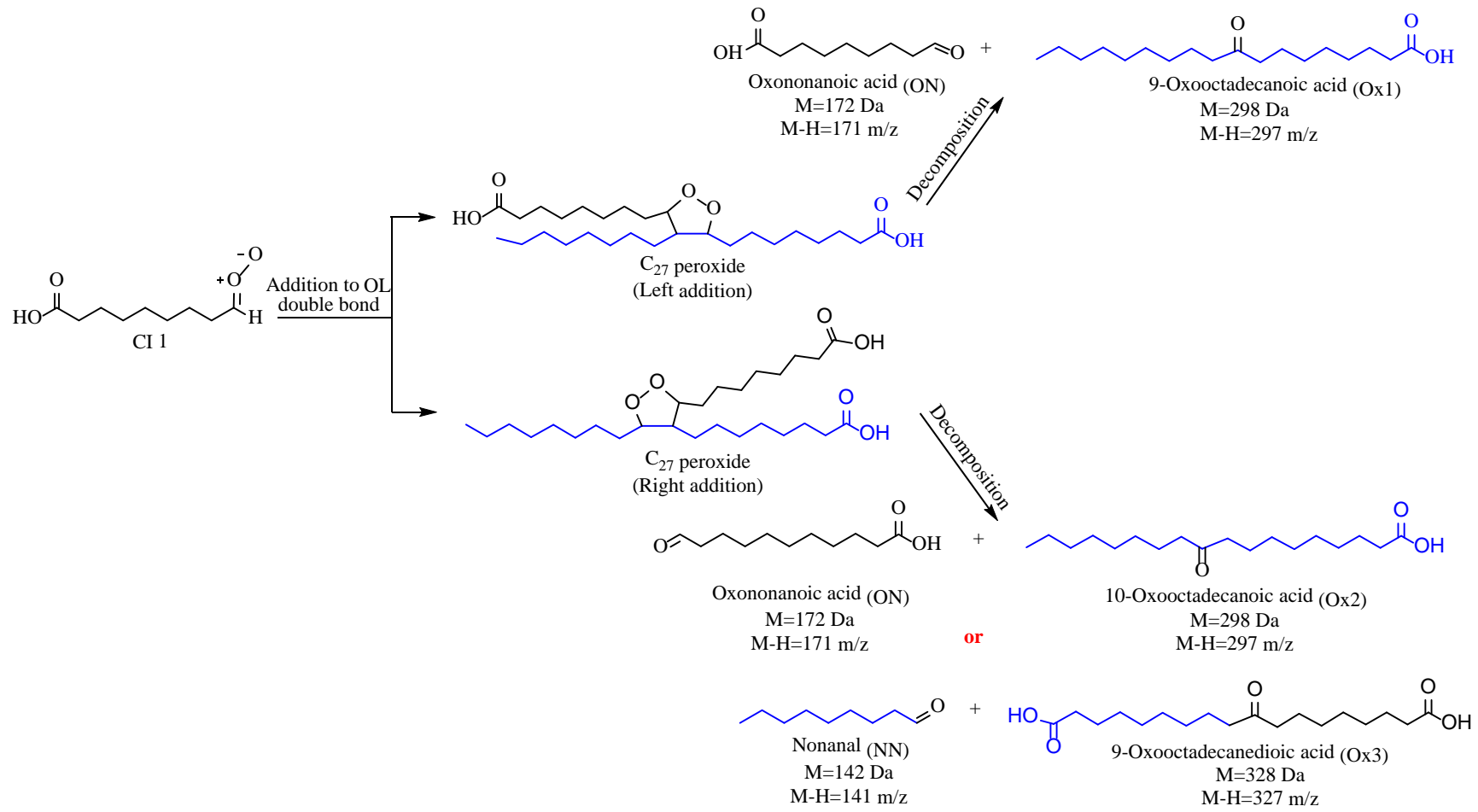

Scheme 2. Potential mechanism and product structures formed as a result of the reaction between CI1 and the alkene functionality of OL.

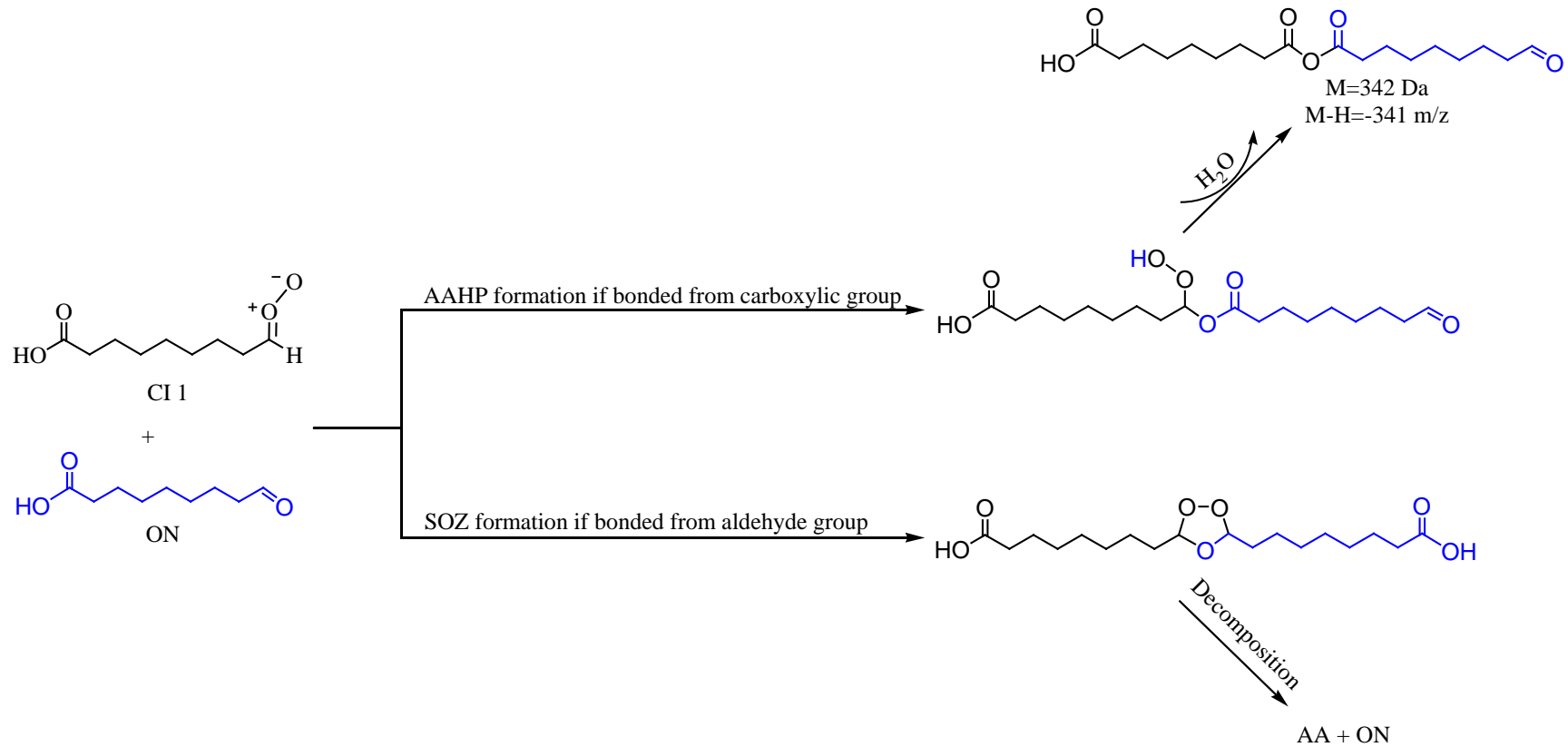

Scheme 3. Suggested reaction pathways and products of the secondary reaction between CI1 and ON.

since most particles were in the size range $0.3-0.5 \mu \mathrm{m}$ this analysis will be biased towards this size fraction. The overall size distribution of the analysed particles was in the range $0.2-2.1 \mu \mathrm{m}$ as measured by ATOFMS; see Fig. 7c.
It can be clearly observed that the composition of aged particles is highly dependent on particle size. Firstly, larger particles contain more unreacted OL than smaller particles. This can be understood in terms of OL diffusivity within the particle and ozone flux into the particle. As the reaction pro- 


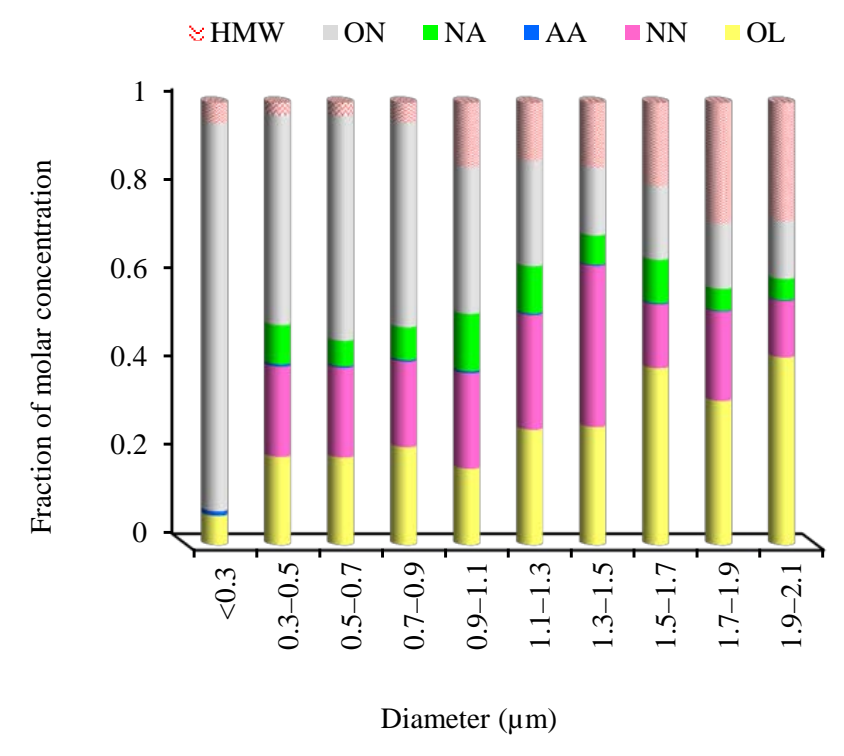

(a)

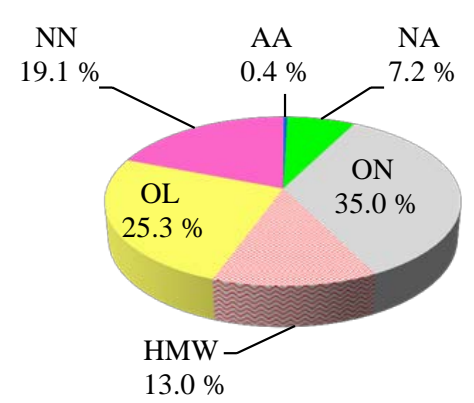

(b)

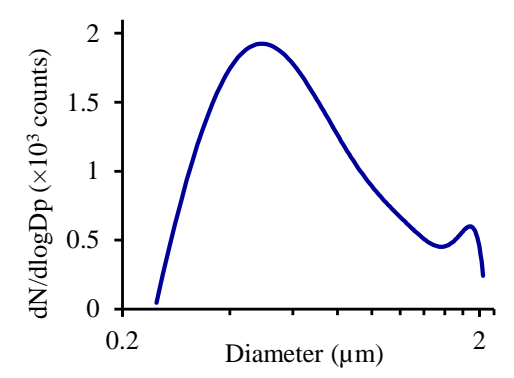

(c)

Figure 7. ATOFMS data analysis of (a) mole fraction of ozonolysed OL particles, under dry conditions, as a function of particle size; (b) total particle composition as given by mole fraction for all size fractions; and (c) corresponding size distribution of the aged OL aerosol measured by ATOFMS.

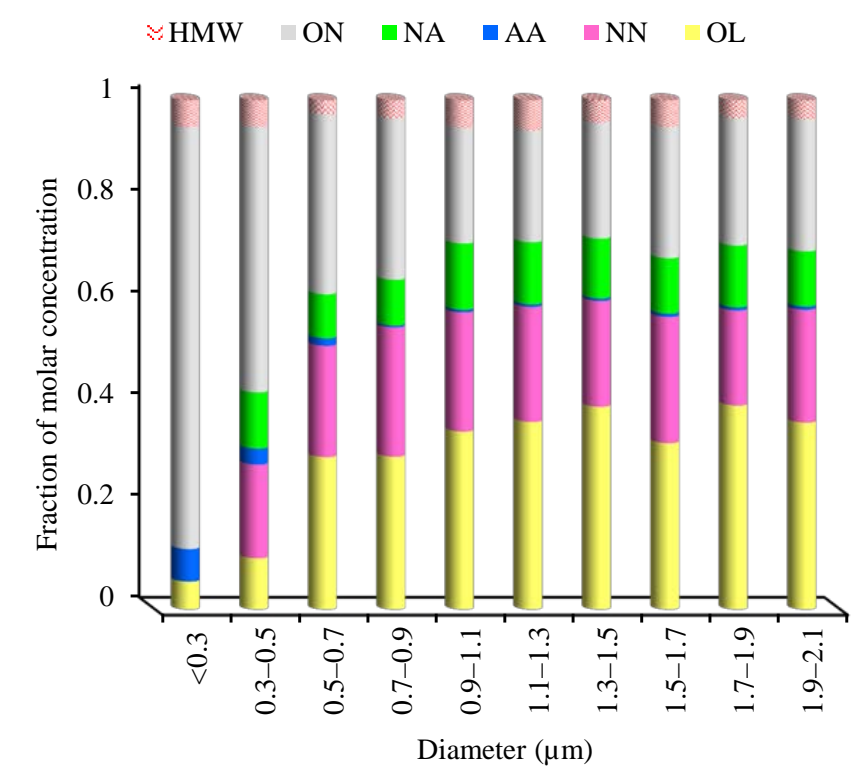

(a)

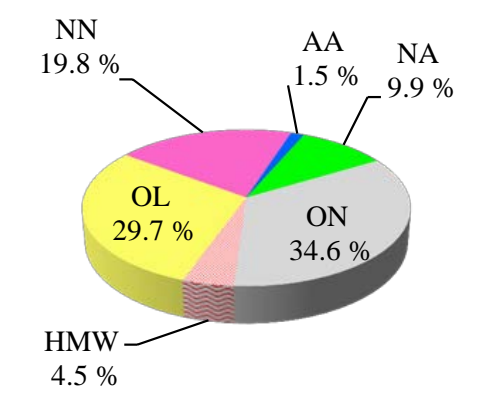

(b)

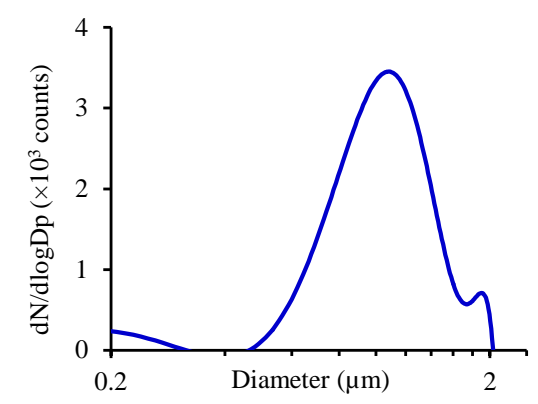

(c)

Figure 8. ATOFMS data analysis of (a) mole fraction of ozonolysed OL particles, under humidified conditions, as a function of particle size; (b) total particle composition as given by mole fraction for all size fractions; and (c) corresponding size distribution of the aged OL aerosol measured by ATOFMS. 
gresses and oxidation products evolve at the reacted surface layer, both OL diffusivity within the particle and ozone diffusion to the bulk are reduced. Smith et al. (2002) reported a low decay of OL in larger particles which was attributed by the limited OL diffusivity within the large particles. However, OL molecules in smaller particles (at a diameter size of $200 \mathrm{~nm}$ and less) are homogeneous in concentration and thus particles at this size and below are well mixed (Smith et al., 2002; Pfrang et al., 2010), facilitating the oxidation process and therefore the smaller the portion of unreacted OL. Additionally, in a simulation study, Shiraiwa et al. (2010) showed that ozone uptake drops upon reaction, attributed to a decrease in OL concentration at the particle surface (while it remains constant in the inner particle bulk due to rapid bulk diffusion). It is therefore reasonable to conclude that the larger the particle the less the molar ratio of $\mathrm{O}_{3}: \mathrm{OL}$ in the overall particle phase and hence the smaller the degree of oxidation and the greater proportion of unreacted OL. The fraction of $\mathrm{NN}$ in the particle tends to increase with particle size. The smallest size fraction contained only negligible amounts of NN. The vapour pressure of $\mathrm{NN}$ is $49.3 \mathrm{~Pa}$ at $25^{\circ} \mathrm{C}$ (Daubert and Danner, 1989) and hence it is a highly volatile species which tends to partition to the vapour phase. In previous studies $\mathrm{NN}$ has been identified as one of the major volatile products (Moise and Rudich, 2002; Thornberry and Abbatt, 2004; Zahardis and Petrucci, 2007; Vesna et al., 2009; Dennis-Smither et al., 2012b), while few investigators detected NN in the particle phase using supermicron (King et al., 2004) and supported millimetre-sized particles (Hung and Ariya, 2007). It is likely that NN has a low condensed phase yield in small particles due to its volatility that results in fast partition to the vapour phase. NN signals, however, were frequently enhanced in large particle spectra since its concentration in these particles was evolved from the secondary reaction within the particles, and products in these particles might reduce the effective vapour pressure of $\mathrm{NN}$. Loss as vapour would also require diffusion within the condensed phase, which takes longer to reach the surface in the larger particles. Wang et al. have argued that all observed $\mathrm{NN}$ in the particle phase was formed via secondary reactions though the study was conduct on pure OL particles of $\sim 100 \mathrm{~nm}$ (Wang et al., 2016).

The mole fraction of AA, which arises from the rearrangement of CI1, was significantly larger in small particles compared to larger particles. It diminished appreciably in the most reacted larger particles, suggesting the involvement of AA in the secondary chemistry associated more with larger particles. NA arising from $\mathrm{CI} 2$ showed a different trend to AA and was not detected in small particles but observed in comparable fractions in larger size bins. This may reflect the volatile nature of NA, which would reduce its impact in secondary chemistry as it tends to partition away from the particle. The steady decrease in ON mole fraction as particle size increases possibly indicates the involvement of $\mathrm{ON}$ in the secondary reactions associated with larger particles.
Figure 7a suggests that reactions in larger particles can appreciably enhance the formation of HMW $(>282 \mathrm{~m} / z)$ products. The chemical composition of larger particles, compared to smaller particles, is characterised by more unreacted OL, increased HMW products, and less AA and ON. The low concentration of OL in small particles, however, minimizes these secondary pathways and maximises the formation of the SOZ, which subsequently dissociates to form the four primary oxidation products. The quantification analysis of processed OL particles by Katrib and co-workers showed no trend for AA with increasing OL layer thickness $(2-30 \mathrm{~nm})$, but high ON yield as compared to AA and NA yields was observed (Katrib et al., 2004), which is very consistent with our findings. They attributed their finding to the reactivity of the AA and NA precursors, i.e. CIs, being scavenged by OL. The presence of HMW products likely leads to greater aerosol viscosity and hence lower diffusion rates within the particle (Hosny et al., 2016). Hence larger particles will likely have slower diffusion rates, which may in part explain the greater proportion of NN in the larger particles. Moreover, measured viscosity of chemically aged aerosol might therefore be expected to vary (increase) substantially with particle size, which is of relevance to the interpretation of aerosol particle viscosity measurements performed on individual supermicron samples.

\subsection{Composition of aged OL particles under wet conditions}

Figure 8 provides the corresponding compositional analysis, by applying SCFs to the raw ATOFMS data, of 1000 aged OL particles that were ozonolysed under humidified conditions. Significant differences in both the size-dependent and average distribution of components between the dry and humidified oxidation runs were observed.

The greatest difference between the dry and wet oxidation data, averaged over all size bins for the complete polydisperse aerosol ensemble, is the reduction in HMW products from $13.0 \%$ under dry conditions compared to $4.5 \%$ under humidified conditions. The proportion of unreacted OL increases under humidified conditions $(29.7 \%)$ compared to dry conditions $(25.3 \%)$. Whilst OL is negligibly hygroscopic, ozonolysed OL is slightly hygroscopic (Lee et al., 2012). This slight hygroscopicity suggests that particle-phase water could act as a reactant. The differences in composition between the dry and the humidified experiments could be explained by the preferential reactivity of CIs with water molecules compared to OL, thereby resulting in a lower OL consumption under wet conditions. This chemistry results in less destruction of additional OL molecules via the secondary pathways and hence the higher portion of unreacted OL and the limited amount of HMW products, which are observed concomitantly under wetter conditions. The size distribution data from the SMPS, which indicated less mass loss during the humidified oxidation, support this argument. AA in small 


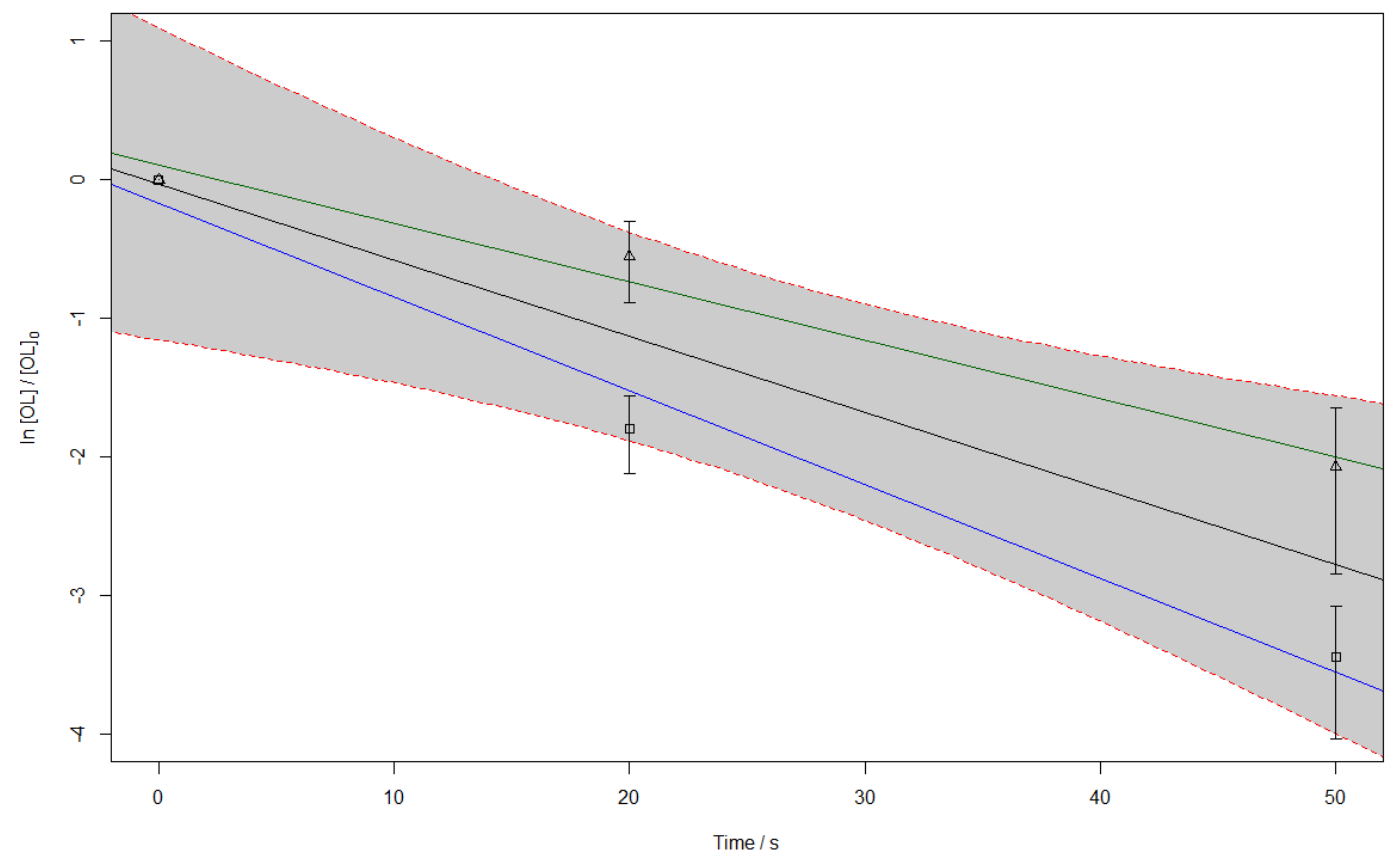

Figure 9. Reactive decay of oleic acid as a function of time for particles in the size range $0.4-0.5 \mu \mathrm{m}$ (mean particle diameter $=0.48 \mu \mathrm{m})$. Square symbols are measurements under dry conditions $(\mathrm{RH}=0.5 \%)$; triangle symbols are measurements under humid conditions $(\mathrm{RH}=65 \%)$; black line is the linear fit of combined dry and humid data; blue line is the linear fit of dry data set; green line is the linear fit of humid data set; grey shading is the confidence limits for the linear fit to the combined data set at the $95 \%$ confidence limits for prediction. Error bars on the individual data points are $2 \times$ the standard error of the mean.

particle sizes showed a significant change in these experiments. The observed amount of AA in the smallest particles $(300 \mathrm{~nm})$ increased under humid condition (Figs. 8 and 7). This result is partially supported by the study of Vesna et al. (2009), who used smaller particles (geometric mean diameter of $78 \mathrm{~nm}$ ) and reported a similar trend with the smallest size bin of the particles in this study. The increase in the AA portion observed in response to the increase in the $\mathrm{RH}$ is consistent with our findings and it is attributed to water interference in suppressing secondary reaction of AA with CIs, although Vesna et al. (2009) report a higher abundance of "unidentified products".

\subsection{Kinetics of oleic acid ozonolysis and product formation}

The kinetics of the ozonolysis of a near-monodisperse sized ensemble of oleic acid particles in the size range of 0.4 $0.5 \mu \mathrm{m}$ with a mean diameter of $0.48 \mu \mathrm{m}$ was investigated. Through the use of three different sized aerosol flow tubes (AFT), but with otherwise identical conditions to the experimental set-up detailed previously, the interaction time between ozone and oleic acid particles could be obtained at 20, 50 , and $135 \mathrm{~s}$. The longest time was the same as that used in the product distribution study shown in Figs. 7 and 8. In the absence of $\mathrm{O}_{3}$ the effective interaction time is zero. We observed that the concentration of oleic acid was negligible at the longest interaction time (135 s) and hence the kinetics could only be followed in the time range of $0-50 \mathrm{~s}$. The kinetics of the loss of OL were measured under both dry $(0.5 \%$ $\mathrm{RH})$ and humidified $(65 \% \mathrm{RH})$ conditions. The kinetics of oleic acid loss appear to be a little faster under dry conditions compared to humid conditions. This is surprising since oleic acid is only marginally hygroscopic and any water that is available will likely partition to the hygroscopic region of the molecule around the carboxylic acid functional group and not the lipophilic $\mathrm{C}=\mathrm{C}$ double bond where the ozonolysis occurs.

The measured data, for both the dry and humid runs, show a linear relationship between the plot of $\ln \mathrm{S}(\mathrm{OL}) / \mathrm{S}\left(\mathrm{OL}_{0}\right)$ vs. interaction time, where $\mathrm{S}(\mathrm{OL})$ is the oleic acid signal, as shown in Fig. 9. This is consistent with surface limited reaction, as described by Case 3 kinetics initially proposed by Hearn et al. (2005). Using the same approach as Hearn et al. (2005), using the Case 3 kinetics approach to derive gamma uptake coefficients $(\gamma)$, we obtain $\gamma_{\text {dry }}=3.86 \pm 0.54 \times 10^{-4}$ and $\gamma_{\text {wet }}=2.40 \pm 0.36 \times 10^{-4}$, and the value when both the dry and wet data are combined is $\gamma_{\text {combined }}=3.13 \pm 1.49 \times 10^{-4}$, where the stated errors are $2 \times$ the standard error of the mean. These values are similar to previous measurements of $\gamma$, e.g. Hearn and Smith (2004), Moise and Rudich (2002), Hearn et al. (2005), Thornberry and Abbatt (2004), Ziemann (2005), and Knopf et al. (2005). The observed kinetics is what we expect when the initial 

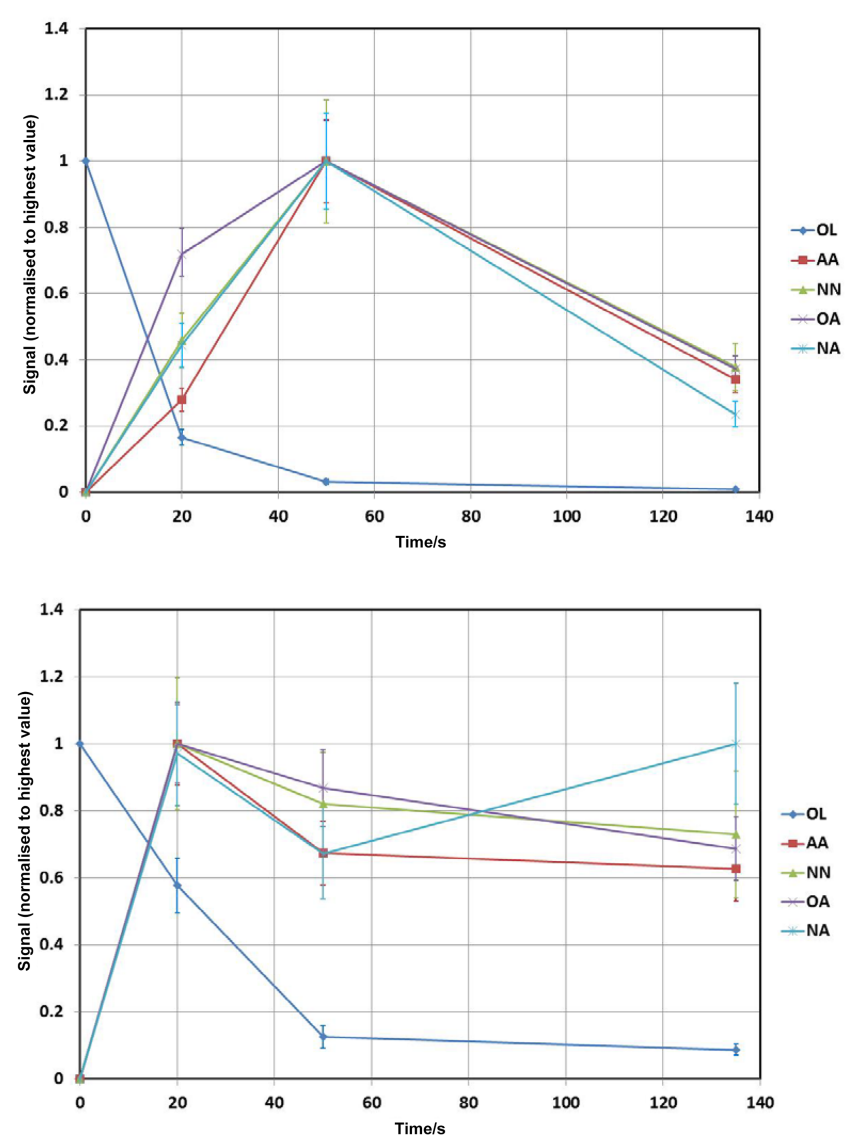

Figure 10. Time-dependent signals of oleic acid and the four major first generation ozonolysis products. The upper graph was obtained under dry conditions $(\mathrm{RH}=0.5 \%)$ and the lower graph was obtained under wet conditions $(\mathrm{RH}=65 \%)$. To aid ease of comparison of the different time series, the signals for all investigated species have been normalised relative to the peak signal achieved by the species investigated. Error bars are $1 \times$ the standard error of the mean.

reaction between $\mathrm{OL}$ and $\mathrm{O}_{3}$ occurs at or near the surface. Steimer et al. (2016) provide detailed mathematical analysis showing, for this reaction scenario, that the degradation rate of OL is size dependent but the uptake coefficient remains the same. It follows that the kinetics of the ozonolysis of OL is surface limited rather than reaction diffusion limited; detailed discussion of different kinetic regimes is provided in Berkemeier et al. (2013).

In addition to the oleic acid reactive decay kinetics, we also observed the time-dependent formation of the four major first generation reaction products NA, AA, NN, and ON, see Fig. 10. The HMW products were not observable in these experimental runs which are consistent with the low levels observed in Figs. 7 and 8 in the $0.3-0.5 \mu \mathrm{m}$ size bin. It is noted that low levels of HMW products were observed in the product distribution study but longer averaging times were used. It is clear that whilst the kinetics of oleic acid loss is very similar under both dry and humidified conditions, there are obvious differences in the formation kinetics of the four major first generation reaction products. In particular, under dry conditions the reaction products form more promptly, and once formed stay at relatively similar concentrations. Under humidified conditions the formation of the peak concentration of the products is slower but also their subsequent loss is more substantial. The kinetic data do not provide any definitive mechanistic understanding. However, these results are consistent with the hypothesis that water can act as a reactant with the CI, thereby reducing the amount of secondary chemistry observed between OL and the primary reaction products, and thus the more stable product distribution after the initial ozonolysis step.

\subsection{Implications for ageing atmospheric organic aerosol}

The observed reactions could have consequences for the ability of OL-derived particles (and OA of comparable functionality) to act as cloud condensation nuclei (CCN). Hygroscopicity greatly enhances the ability of particles to act as CCN and, consequently, oxidised particles containing a larger proportion of shorter-chain polar molecules are likely to be the most effective $\mathrm{CCN}$ for a given particle size. King et al. (2009) use Köhler theory to demonstrate that the more oxidised particles will activate at a lower supersaturation than unreacted OL particles. However, the reduction in particle size which accompanies the loss of $\mathrm{NN}$ to the vapour phase will work in the opposite sense of increasing the critical supersaturation due to an increased Kelvin effect, at least for the smaller particles. However, since particles in the atmosphere are typically mixed and hence unlikely to comprise purely OL, even when emitted, such a discussion is likely to be of very limited relevance to atmospheric behaviour.

Heterogeneous reactions of organic particles directly alter the size, density, and chemical composition of the particles. These are the key parameters controlling the particle's lifetime in the atmosphere and optical properties. While the size of the particle has considerable impact on the deposition velocity, wet scavenging efficiency, and scattering of light, the identity of the species within the particle is the principal characteristic driving light absorption. The aging of organic aerosol can result in the formation of light absorbing species. The large numbers of organic functionalities in SOA such as carboxylate, hydroxyl, ketone, and aldehyde groups may result in an absorbing matrix that can exhibit optical properties dramatically different from those of parent molecules. Particles containing light absorbers may lead to heating of the lower atmosphere, resulting in positive global radiative forcing. The impact of SOA on global radiative forcing is thus one of the largest uncertainties in atmospheric science. However, the presence of absorbing compounds in organic particles can stimulate photosensitisation processes which might lead to either reduction and oxidation of intermediates and 
products (Kolb et al., 2010). For the reasons outlined above, because of the internally mixed nature of airborne particles, closer examination of the properties of oxidised OL particles is unlikely to be of major relevance to prediction of the properties of atmospheric aerosol.

\section{Conclusions}

This study demonstrates a link between the particle size and reaction mechanisms within OL aerosol. Aged finer particles are likely to be more hydrophilic due to the oxidation of the OL in the particles and the formation of an early generation of more polar and hence more hygroscopic oxidation products. However, the combination of unreacted OL, HMW products and volatile product observed in large particles suggests overall hydrophobicity of larger particles. The difference in the reactivity of OL at different relative humidities with less OL destruction observed under humid conditions can be explained by the preference of CIs for reaction with water molecules over the reaction with OL, which results in less oligomerisation.

There has been some speculation in the literature as to the effects of oxidation upon atmospherically relevant properties of OL particles, such as their ability to act as CCN. However, the relevance of extrapolation to the atmospheric context, except in a generic sense, is extremely limited due to the complex internal mixing of atmospheric particles, even when emitted, and hence the extreme improbability of pure OL particles existing in the atmosphere. However, in our view, the value of studies such as this is in the enhanced mechanistic understanding gained from treating OL oxidation by ozone as a model system. In particular, there is limited understanding of processes leading to the formation of highly functionalised oxidised high molecular weight products, such as those observed in this work.

\section{Data availability}

Original research data are available from the authors on request.

\section{The Supplement related to this article is available online at doi:10.5194/acp-16-15561-2016-supplement.}

Acknowledgements. Suad S. Al-Kindi is pleased to acknowledge financial support for her studentship from the government of Oman. This work was funded in part by the Natural Environment Research Council (NERC) project NE/G009031/1, Artificial Chemical Ageing of Ambient Atmospheric Aerosol.

Edited by: M. Ammann

Reviewed by: two anonymous referees

\section{References}

Allen, J. O.: Quantitative analysis of aerosol time-of-flight mass spectrometry data using YAADA, Arizona States, Arizona State University, 65, 2004.

Allen, J. O., Bhave, P. V., Whiteaker, J. R., and Prather, K. A.: Instrument busy time and mass measurement using aerosol timeof-flight mass spectrometry, Aerosol Sci. Technol., 40, 615-626, 2006.

Andrews, E. and Larson, S. M.: Effect of surfactant layers on the size changes of aerosol particles as a function of relative humidity, Environ. Sci. Technol., 27, 857-865, 1993.

Berkemeier, T., Huisman, A. J., Ammann, M., Shiraiwa, M., Koop, T., and Pöschl, U.: Kinetic regimes and limiting cases of gas uptake and heterogeneous reactions in atmospheric aerosols and clouds: a general classification scheme, Atmos. Chem. Phys., 13, 6663-6686, doi:10.5194/acp-13-6663-2013, 2013.

Bhave, P. V., Allen, J. O., Morrical, B. D., Fergenson, D. P., Cass, G. R., and Prather, K. A.: A field-based approach for determining ATOFMS instrument sensitivities to ammonium and nitrate, Environ. Sci. Technol., 36, 4868-4879, 2002.

Carlton, A. G., Pinder, R. W., Bhave, P. V., and Pouliot, G. A.: To what extent can biogenic SOA be controlled?, Environ. Sci. Technol., 44, 3376-3380, 2010.

Chan, M. N., Nah, T., and Wilson, K. R.: Real time in situ chemical characterization of sub-micron organic aerosols using Direct Analysis in Real Time mass spectrometry (DART-MS): the effect of aerosol size and volatility, Analyst, 138, 3749-3757, 2013.

Dall'Osto, M., Harrison, R. M., Beddows, D. C., Freney, E. J., Heal, M. R., and Donovan, R. J.: Single-particle detection efficiencies of aerosol time-of-flight mass spectrometry during the North Atlantic marine boundary layer experiment, Environ. Sci. Technol., 40, 5029-5035, 2006.

Dall'Osto, M. and Harrison, R. M.: Urban organic aerosols measured by single particle mass spectrometry in the megacity of London, Atmos. Chem. Phys., 12, 4127-4142, doi:10.5194/acp12-4127-2012, 2012.

Daubert, T. E. and Danner R. P.: Physical and thermodynamic properties of pure chemicals: Data compilation, Taylor \& Francis, 1989.

Dennis-Smither, B. J., Hanford, K. L., Kwamena, N.-O. A., Miles, R. E. H., and Reid, J. P.: Phase, morphology, and hygroscopicity of mixed oleic acid/sodium chloride/water aerosol particles before and after ozonolysis, J. Phys. Chem. A, 116, 6159-6168, 2012a.

Dennis-Smither, B. J., Miles, R. E. H., and Reid, J. P.: Oxidative aging of mixed oleic acid/sodium chloride aerosol particles, J. Geophys. Res.-Atmos., 117, D20204, doi:10.1029/2012JD018163, 2012b.

Fergenson, D. P., Song, X.-H., Ramadan, Z., Allen, J. O., Hughes, L. S., Cass, G. R., Hopke, P. K., and Prather, K. A.: Quantification of ATOFMS data by multivariate methods, Anal. Chem., 73, 3535-3541, 2001.

Finlayson-Pitts, B. J. and Pitts Jr, J. N.: Analytical methods and typical atmospheric concentrations for gases and particles. Chemistry of the upper and lower atmosphere, Academic Press, San Diego, 11, 547-656, 2000

Gallimore, P. J., Achakulwisut, P., Pope, F. D., Davies, J. F., Spring, D. R., and Kalberer, M.: Importance of relative humidity in the oxidative ageing of organic aerosols: case study of the ozonolysis 
of maleic acid aerosol, Atmos. Chem. Phys., 11, 12181-12195, doi:10.5194/acp-11-12181-2011, 2011.

Gard, E., Mayer, J. E., Morrical, B. D., Dienes, T., Fergenson, D. P., and Prather, K. A.: Real-time analysis of individual atmospheric aerosol particles:? Design and performance of a portable ATOFMS, Anal. Chem., 69, 4083-4091, 1997.

Gard, E. E., Kleeman, M. J., Gross, D. S., Hughes, L. S., Allen, J. O., Morrical, B. D., Fergenson, D. P., Dienes, T., Gälli, M. E., Johnson, R. J., Cass, G. R., and Prather, K. A.: Direct observation of heterogeneous chemistry in the atmosphere, Science, 279, 1184-1187, 1998.

Goldstein, A. H. and Galbally, I. E.: Known and unexplored organic constituents in the Earth's atmosphere, Environ. Sci. Technol., 41, 1515-1521, 2007.

Gonzalez-Labrada, E., Schmidt, R., and DeWolf, C. E.: Kinetic analysis of the ozone processing of an unsaturated organic monolayer as a model of an aerosol surface, Phys. Chem. Chem. Phys., 9, 5814-5821, 2007.

Grimm, R. L., Hodyss, R., and Beauchamp, J. L.: Probing interfacial chemistry of single droplets with field-induced droplet ionization mass spectrometry:? Physical adsorption of polycyclic aromatic hydrocarbons and ozonolysis of oleic acid and related compounds, Anal. Chem., 78, 3800-3806, 2006.

Gross, D. S., Galli, M. E., Silva, P. J., Wood, S. H., Liu, D.-Y., and Prather, K. A.: Single particle characterization of automobile and diesel truck emissions in the Caldecott Tunnel, Aerosol Sci. Technol., 32, 152-163, 2000.

Harrison, R. M.: Pollution: Causes, Effects and Control, Fifth Edition, Royal Society of Chemistry, Cambridge, 2014.

Hearn, J. D. and Smith, G. D.: Kinetics and product studies for ozonolysis reactions of organic particles using aerosol CIMS, J. Phys. Chem. A, 108, 10019-10029, 2004.

Hearn, J. D., Lovett, A. J., and Smith, G. D.: Ozonolysis of oleic acid particles: evidence for a surface reaction and secondary reactions involving Criegee intermediates, Phys. Chem. Chem. Phys., 7, 501-511, 2005.

Hosny, N. A., Fitzgerald, C., Tong, C., Kalberer, M., Kuimova, M. K., and Pope, F. D.: Fluorescent lifetime imaging of atmospheric aerosols: a direct probe of aerosol viscosity, Faraday Discuss., 165, 343-356, 2013.

Hosny, N. A., Fitzgerald, C., Vyšniauskas, A., Athanasiadis, A., Berkemeier, T., Uygur, N., Pöschl, U., Shiraiwa, M., Kalberer, M., Pope, F., and Kuimova, M. K.: Direct imaging of changes in aerosol particle viscosity upon hydration and chemical aging, Chem. Sci., 7, 1357-1367, 2016.

Hung, H.-M., Katrib, Y., and Martin, S. T.: Products and mechanisms of the reaction of oleic acid with ozone and nitrate radical, J. Phys. Chem. A, 109, 4517-4530, 2005.

Hung, H.-M. and Ariya, P.: Oxidation of oleic acid and oleic acid/sodium chloride(aq) mixture droplets with ozone: Changes of hygroscopicity and role of secondary reactions, J. Phys. Chem. A, 111, 620-632, 2007.

Hung, H.-M. and Tang, C.-W.: Effects of temperature and physical state on heterogeneous oxidation of oleic acid droplets with ozone, J. Phys. Chem. A, 114, 13104-13112, 2010.

Katrib, Y., Martin, S. T., Hung, H.-M., Rudich, Y., Zhang, H., Slowik, J. G., Davidovits, P., Jayne, J. T., and Worsnop, D. R.: Products and mechanisms of ozone reactions with oleic acid for aerosol particles having core-shell morphologies, J. Phys. Chem. A, 108, 6686-6695, 2004.

Katrib, Y., Biskos, G., Buseck, P. R., Davidovits, P., Jayne, J. T., Mochida, M., Wise, M. E., Worsnop, D. R., and Martin, S. T.: Ozonolysis of mixed oleic-acid/stearic-acid particles: Reaction kinetics and chemical morphology, J. Phys. Chem. A, 109, 10910-10919, 2005a.

Katrib, Y., Martin, S. T., Rudich, Y., Davidovits, P., Jayne, J. T., and Worsnop, D. R.: Density changes of aerosol particles as a result of chemical reaction, Atmos. Chem. Phys., 5, 275-291, doi:10.5194/acp-5-275-2005, 2005b.

King, M. D., Thompson, K. C., and Ward, A. D.: Laser Tweezers raman study of optically trapped aerosol droplets of seawater and oleic acid reacting with ozone: Implications for cloud-droplet properties, J. Am. Chem. Soc., 126, 16710-16711, 2004.

King, M. D., Rennie, A. R., Thompson, K. C., Fisher, F. N., Dong, C. C., Thomas, R. K., Pfrang, C., and Hughes, A. V.: Oxidation of oleic acid at the air-water interface and its potential effects on cloud critical supersaturations, Phys. Chem. Chem. Phys., 11, 7699-7707, 2009.

Kolb, C. E., Cox, R. A., Abbatt, J. P. D., Ammann, M., Davis, E. J., Donaldson, D. J., Garrett, B. C., George, C., Griffiths, P. T., Hanson, D. R., Kulmala, M., McFiggans, G., Pöschl, U., Riipinen, I., Rossi, M. J., Rudich, Y., Wagner, P. E., Winkler, P. M., Worsnop, D. R., and O'Dowd, C. D.: An overview of current issues in the uptake of atmospheric trace gases by aerosols and clouds, Atmos. Chem. Phys., 10, 10561-10605, doi:10.5194/acp-1010561-2010, 2010.

Kolb, C. E. and Worsnop D. R.: Chemistry and composition of atmospheric aerosol particles, Annu. Rev. Phys. Chem., 63, 471491, 2012.

Koop, T., Bookhold, J., Shiraiwa, M., and Pöschl, U.: Glass transition and phase state of organic compounds: dependency on molecular properties and implications for secondary organic aerosols in the atmosphere, Phys. Chem. Chem. Phys., 13, 19238-19255, 2011.

Kroll, J. H. and Seinfeld, J. H.: Chemistry of secondary organic aerosol: Formation and evolution of low-volatility organics in the atmosphere, Atmos. Environ., 42, 3593-3624, 2008.

Pradeep Kumar, P., Broekhuizen, K., and Abbatt, J. P. D.: Organic acids as cloud condensation nuclei: Laboratory studies of highly soluble and insoluble species, Atmos. Chem. Phys., 3, 509-520, doi:10.5194/acp-3-509-2003, 2003.

Lee, A. K. Y. and Chan, C. K.: Single particle Raman spectroscopy for investigating atmospheric heterogeneous reactions of organic aerosols, Atmos. Environ., 41, 4611-4621, 2007.

Lee, J. W. L., Carrascon, V., Gallimore, P. J., Fuller, S. J., Bjorkegren, A., Spring, D. R., Pope ,F. D., and Kalberer, M.: The effect of humidity on the ozonolysis of unsaturated compounds in aerosol particles, Phys. Chem. Chem. Phys., 14, 8023-8031, 2012.

Mendez, M., Visez, N., Gosselin, S., Crenn, V., Riffault, V., and Petitprez, D.: Reactive and Nonreactive Ozone Uptake during Aging of Oleic Acid Particles, J. Phys. Chem. A, 118, 9471-9481, 2014.

Moise, T. and Rudich, Y.: Reactive uptake of ozone by aerosolassociated unsaturated fatty acids: Kinetics, Mechanism, and products, J. Phys. Chem. A, 106, 6469-6476, 2002. 
Morris, J. W., Davidovits, P., Jayne, J. T., Jimenez, J. L., Shi, Q., Kolb, C. E., Worsnop, D. R., Barney, W. S., and Cass, G.: Kinetics of submicron oleic acid aerosols with ozone: A novel aerosol mass spectrometric technique, Geophys. Res. Lett., 29, 1357, doi:10.1029/2002GL014692, 2002.

Nash, D. G., Baer, T., and Johnston, M. V.: Aerosol mass spectrometry: An introductory review, Intl J. Mass Spectrom., 258, 2-12, 2006.

Neeb, P., Horie, O., and Moortgat, G. K.: The ethene-ozone reaction in the gas phase, J. Phys. Chem. A, 102, 6778-6785, 1998.

Park, J., Gomez, A. L., Walser, M. L., Lin, A., and Nizkorodov, S. A.: Ozonolysis and photolysis of alkene-terminated selfassembled monolayers on quartz nanoparticles: implications for photochemical aging of organic aerosol particles, Phys. Chem. Chem. Phys., 8, 2506-2512, 2006.

Petters, M. D., Prenni, A. J., Kreidenweis, S. M., DeMott, P. J., Matsunaga, A., Lim, Y. B., and Ziemann, P. J.: Chemical aging and the hydrophobic-to-hydrophilic conversion of carbonaceous aerosol, Geophys. Res. Lett., 33, L24806, doi:10.1029/2006GL027249, 2006.

Pfrang, C., Shiraiwa, M., and Pöschl, U.: Coupling aerosol surface and bulk chemistry with a kinetic double layer model (K2-SUB): oxidation of oleic acid by ozone, Atmos. Chem. Phys., 10, 45374557, doi:10.5194/acp-10-4537-2010, 2010.

Pöschl, U.: Gas-particle interactions of tropospheric aerosols: Kinetic and thermodynamic perspectives of multiphase chemical reactions, amorphous organic substances, and the activation of cloud condensation nuclei, Atmos. Res., 562-573, 2011.

Reynolds, J. C., Last, D. J., McGillen, M., Nijs, A., Horn, A. B., Percival, C., Carpenter, L. J., and Lewis, A. C.: Structural analysis of oligomeric molecules formed from the reaction products of oleic acid ozonolysis, Environ. Sci. Technol., 40, 6674-6681, 2006.

Rudich, Y.: Laboratory perspectives on the chemical transformations of organic matter in atmospheric particles, Chem. Rev., 103, 5097-5124, 2003.

Shiraiwa, M., Pfrang, C., and Pöschl, U.: Kinetic multi-layer model of aerosol surface and bulk chemistry (KM-SUB): the influence of interfacial transport and bulk diffusion on the oxidation of oleic acid by ozone, Atmos. Chem. Phys., 10, 3673-3691, doi:10.5194/acp-10-3673-2010, 2010.

Silva, P. J. and Prather, K. A.: Interpretation of mass spectra from organic compounds in aerosol time-of-flight mass spectrometry, Anal. Chem., 72, 3553-3562, 2000.

Smith, G. D., Woods, E., DeForest, C. L., Baer, T., and Miller, R. E.: Reactive uptake of ozone by oleic acid aerosol particles: Application of single-particle mass spectrometry to heterogeneous reaction kinetics, J. Phys. Chem. A, 106, 8085-8095, 2002.
Steimer, S. S., Lampimäki, M., Coz, E., Grzinic, G., and Ammann, M.: The influence of physical state on shikimic acid ozonolysis: a case for in situ microspectroscopy, Atmos. Chem. Phys., 14, 10761-10772, doi:10.5194/acp-14-10761-2014, 2014.

Sullivan, R. C. and Prather, K. A.: Recent advances in our understanding of atmospheric chemistry and climate made possible by on-line aerosol analysis instrumentation, Anal. Chem., 77, 38613886, 2005.

Thornberry, T. and Abbatt, J. P. D.: Heterogeneous reaction of ozone with liquid unsaturated fatty acids: detailed kinetics and gasphase product studies, Phys. Chem. Chem. Phys., 6, 84-93, 2004.

Vesna, O., Sjogren, S., Weingartner, E., Samburova, V., Kalberer, M., Gäggeler, H. W., and Ammann, M.: Changes of fatty acid aerosol hygroscopicity induced by ozonolysis under humid conditions, Atmos. Chem. Phys., 8, 4683-4690, doi:10.5194/acp-84683-2008, 2008.

Vesna, O., Sax, M., Kalberer, M., Gaschen, A., and Ammann, M.: Product study of oleic acid ozonolysis as function of humidity, Atmos. Environ., 43, 3662-3669, 2009.

von Hessberg, C., von Hessberg, P., Pöschl, U., Bilde, M., Nielsen, O. J., and Moortgat, G. K.: Temperature and humidity dependence of secondary organic aerosol yield from the ozonolysis of $\beta$-pinene, Atmos. Chem. Phys., 9, 3583-3599, doi:10.5194/acp9-3583-2009, 2009.

Wang, M., Yao, L., Zheng, J., Wang, X., Chen, J., Yang, X., Worsnop, D. R., Donahue, N. M., and Wang, L.: Reactions of atmospheric particulate stabilized Criegee intermediates lead to high-molecular-weight aerosol components, Environ. Sci. Technol., 50, 5072-5710, 2016.

Zahardis, J., LaFranchi, B. W., and Petrucci, G. A.: Photoelectron resonance capture ionization-aerosol mass spectrometry of the ozonolysis products of oleic acid particles: Direct measure of higher molecular weight oxygenates, J. Geophys. Res.-Atmos., 110, D08307, doi:10.1029/2004JD005336, 2005.

Zahardis, J., LaFranchi, B. W., and Petrucci, G. A.: Direct observation of polymerization in the oleic acid-ozone heterogeneous reaction system by photoelectron resonance capture ionization aerosol mass spectrometry, Atmos. Environ., 40, 1661-1670, 2006.

Zahardis, J. and Petrucci, G. A.: The oleic acid-ozone heterogeneous reaction system: products, kinetics, secondary chemistry, and atmospheric implications of a model system - a review, Atmos. Chem. Phys., 7, 1237-1274, doi:10.5194/acp-7-1237-2007, 2007.

Ziemann, P. J.: Aerosol products, mechanisms, and kinetics of heterogeneous reactions of ozone with oleic acid in pure and mixed particles, Faraday Discuss., 130, 469-490, 2005. 